\title{
Attaching Strong Auxiliary Acceptor onto B-N-Containing Multiple Resonance Framework and Achieving Highly Efficient Electroluminescence with Ultrahigh Color Purity
}

Yincai Xu, ${ }^{[\mathrm{a}]}$ Chenglong Li ${ }^{*[\mathrm{a}]}$ Zhiqiang Li, ${ }^{[\mathrm{b}]}$ Jiaxuan Wang, ${ }^{[\mathrm{a}]}$ Jianan Xue, ${ }^{[\mathrm{a}]}$ Qingyang Wang, ${ }^{[\mathrm{a}]}$ Xinliang Cai, ${ }^{[\mathrm{a}]}$ and Yue Wang ${ }^{*[\mathrm{a}, \mathrm{b}]}$

a Y. Xu, Dr. C. Li, J. Wang, J. Xue, Q. Wang, X. Cai and Prof. Y. Wang State Key Laboratory of Supramolecular Structure and Materials College of Chemistry, Jilin University, Changchun 130012, P. R. China

b Dr. Z. Li, Prof. Y. Wang

Jihua Laboratory, 28 Huandao South Road, Foshan 528200, Guangdong Province, P. R. China.

Authors to whom correspondence should be addressed:

chenglongli@jlu.edu.cn (C. Li), yuewang@jlu.edu.cn (Y. Wang)

Keywords: multiple resonance, thermally activated delayed fluorescence, narrowband green OLED, high color purity and efficiency

Abstract: The development and enrichment of organic materials with narrowband emission in longer wavelength region beyond $515 \mathrm{~nm}$ still remains a great challenge. Herein, a series of unique narrowband green thermally activated delayed fluorescence (TADF) emitters has been constructed based on a synthetic strategy by localized attachment of acceptor onto B-N-containing multiple resonance (MR) framework. The precise modulation of acceptor is an ingenious approach for achieving bathochromic shift and narrowband emission, simultaneously. Furthermore, an important synthetic methodology has been proposed to functionalize MR skeleton and generate a universal building block, which can be utilized to construct multifarious TADF materials with ultrahigh color purity through a simple one-step Suzuki coupling reaction. The DtCzB- 
TPTRZ-based organic light-emitting diode (OLED) exhibits pure green emission with Commission Internationale de L'Eclairage (CIE) coordinates of $(0.23,0.68)$, and achieves remarkable maximum external quantum efficiency (EQE) of 30.6\% with low efficiency roll-off.

\section{Introduction}

Purely organic thermally activated delayed fluorescence (TADF) materials have been established as one of the most promising emitters for organic light-emitting diodes (OLEDs), which can capture electro-generated dark triplet exciton for light emission and achieve highly efficient conversion of electric energy to light via endothermally assisted reverse intersystem crossing (RISC) process from the lowest triplet state $\left(\mathrm{T}_{1}\right)$ to the lowest singlet state $\left(\mathrm{S}_{1}\right) \cdot{ }^{[1]}$ According to Boltzmann statistics, a sufficiently small singlet-triplet energy splitting $\left(\Delta E_{\mathrm{ST}}\right)$ between the $\mathrm{S}_{1}$ and $\mathrm{T}_{1}$ is indispensable to guarantee the effective RISC process, which can be achieved by diminishing the overlap of the highest occupied molecular orbital (HOMO) and the lowest unoccupied molecular orbital (LUMO). ${ }^{[2]}$ The commonly adopted strategy is to apply intramolecular charge transfer (ICT) configuration with the aid of donor-acceptor (DA) molecular skeleton, which inevitably induces remarkable Stokes shift. Meanwhile, the broad emission spectra are generated from vibronic coupling between the ground state and singlet excited state as well as structural relaxation of the $\mathrm{S}_{1}$ state. $^{[3]}$ As for display applications, the broadband emission is tremendously lack of high color purity and cannot achieve wide color gamut display that is fairly important for accurate regeneration of the authentic colors of image content. ${ }^{[4]}$ Although the excellent color 
purity can be obtained by cutting off the margin region of original broadband electroluminescence (EL) with color filters or optical microcavities, the drawback is that these treatments considerably sacrifices the actual efficiency value of OLEDs. ${ }^{[5]}$ Encouragingly, the most highlighted advantage of D-A structure is the extreme flexibility of emission maximum regulation spanning, which is wide enough within visible spectral region due to the ICT characteristic.

Recently, multiple resonance (MR) type TADF materials based on B-N-containing conjugated molecules, which are composed of rigid skeletons with alternate arrangements of HOMO and LUMO, have shown considerable potential for fabricating highly efficient OLEDs with extraordinary color purity (Scheme 1a). ${ }^{[6]}$ MR-type TADF molecules demonstrate the unique excitonic features of narrow full-width at half-maximum (FWHM), giant oscillator strength $(f)$, large extinction coefficient and near-unity photoluminescence quantum yield (PLQY). Although it is relatively easy to synthesize MR-type TADF emitters with high-efficiency and narrowband emission in blue and sky-blue regions, narrowband TADF emitters in longer wavelength region with emission maximum over $515 \mathrm{~nm}$ remain scarce. To construct a wide color gamut full-color display, it requires not only narrowband deep blue emitters but also ultrapure green and red ones that comply with the Commission Internationale de L'Eclairage (CIE) coordinates requirements defined by National Television System Committee (NTSC). Therefore, it is critical to further explore emitters with narrowband emission in longer wavelength region for both academic research and commercial applications. 
Only a few MR-type TADF molecules emit in longer wavelength region have been reported up to now. ${ }^{[6 i-n]}$ The MR molecules were synthesized via tandem lithiationborylation-annulation reaction or one-shot electrophilic $\mathrm{C}-\mathrm{H}$ borylation reaction. Therefore, the adopted synthesis method for target molecules was only based on the borylation of aromatic amine ligands that were previously synthesized, which severely restricted the expansion of MR molecular family. The reported synthetic method for MR molecules suffers several major disadvantages. First, the low yield of the borylation reaction involving large aromatic amine ligand with complex structure leads to a complex final reaction mixture, which contains the product molecule, the amine ligands, borylation isomers and other by-products with very similar polarity and same or very near molecular weight, imposing difficulties in the separation and purification. Second, for the ligands with stronger electron acceptor moieties, such as 1,3,5-triazine, pyridazine, pyrimidine and pyrazine groups, the borylation on the para-carbon position of acceptor-substituted phenyl-ring is not conducive. In other words, this class ligands cannot directly coordinate with boron and form MR framework (Figure S1). These electron withdrawing groups (EWGs) can reduce the electron density of para-carbon atom and thus suppress the $\mathrm{C}-\mathrm{H}$ borylation reaction with boron tribromide/triiodide. ${ }^{[60]}$ Even if alkyllithium is employed as dehydrogenation/dehalogenation reagent for the ligands with most EWGs such as cyano or carbonyl groups, the side chemical reactions can take place at high temperature $\left(c a .60^{\circ} \mathrm{C}\right)$ and transform cyano or carbonyl groups into undesired or unforeseen groups. ${ }^{[61]}$ 


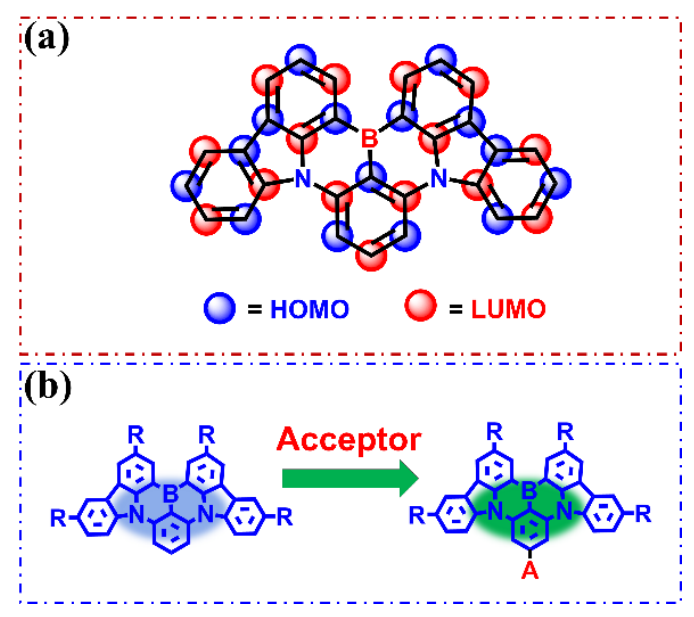

Scheme 1. (a) The MR framework. (b) The diagram sketch of attaching acceptor onto MR framework.

In principle, the introduction of strong acceptor into the para-carbon position of Bsubstituted phenyl-ring can remarkably depress the energy level of LUMO (Scheme 1b), while slightly change that of HOMO, resulting in an obvious decrease of band gap and red-shift emission. ${ }^{[6 \mathrm{i}, 6 \mathrm{k}]}$ A precisely localized introduction of strong acceptor should be an efficient approach to shift the emission to longer wavelength region. Therefore, developing modified methodology of MR framework with strong auxiliary acceptor is a significant challenge for achieving organic emitters with narrowband emission in longer wavelength region. Here, we present a straightforward synthetic methodology to functionalize MR skeleton that can be attached onto strong acceptors. In this method, the parent molecule DtCzB was selected as the original skeleton (Figure 1), which could be converted into the key intermediate DtCzB-Bpin with high yield by catalytic amount di-mu-methoxobis(1,5-cyclooctadiene)diiridium (I) $\left(\left[\operatorname{Ir}(\mathrm{COD})\left(\mathrm{OCH}_{3}\right)\right]_{2}\right)$ and 4,4'-di-tert-butyl-2,2'-bipyridine (dtbpy) (Figure 1b). Then, a wide variety of functional groups could be introduced only followed by one step uncomplicated Pdmediated Suzuki coupling reaction, resulting in diverse efficient emitters with high 
color purity. Moreover, it can be inferred that the synthetic method of functionalizing $\mathrm{DtCzB}$ can be extended to its carbazole-based analogues. Herein, four representative molecules were presented and employed to demonstrate the outstanding performance of our synthetic approach (Figure 1a). Significantly, the resulted DtCzB-TPTRZ-based OLED exhibits ultrapure green emission with CIE coordinates of $(0.23,0.68)$ and remarkable maximum EQE of $30.6 \%$ as well as low efficiency roll-off.

\section{Results and Discussions}

\subsection{Synthesis and Characterization}

Starting from the parent molecule DtCzB, four target molecules were successfully prepared through two easy handle steps. The key step for obtaining the target compounds was the successful synthesis of precursor DtCzB-Bpin. In the presence of catalytic amount $\left[\operatorname{Ir}(\mathrm{COD})\left(\mathrm{OCH}_{3}\right)\right]_{2}(1 \%$ molar stoichiometric ratio) and dtbpy $(2 \%$ molar stoichiometric ratio), which are commercially available at low prices, the intermediate DtCzB-Bpin can be easily transformed via DtCzB and bis(pinacolato)diboron with high yield, ${ }^{[7]}$ and then employed as a building block for the construction of versatile compounds through one-step Suzuki coupling reaction (see Supporting Information). The preparation processes are robust for manufacturing the target compounds in a commercial scale. The detailed synthetic procedures are shown in Supporting Information and the NMR spectra of all compounds are shown in Figures S2-S6. 


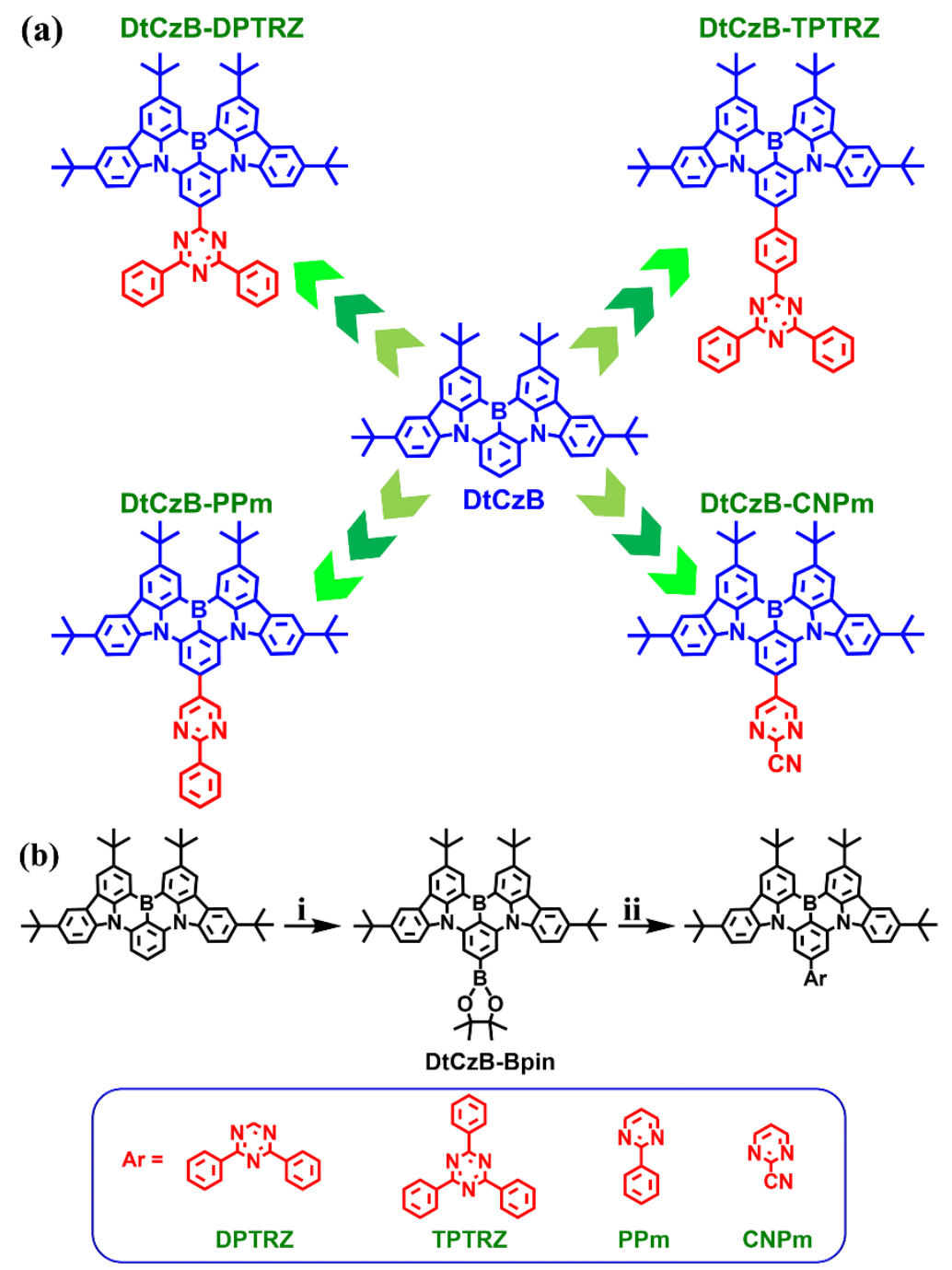

Figure 1. (a) Chemical structures of the investigated compounds. (b) Synthetic procedures: (i) bis(pinacolato)diboron, $\left[\operatorname{Ir}(\mathrm{COD})\left(\mathrm{OCH}_{3}\right)\right]_{2}$, dtbpy, tetrahydrofuran, reflux. (ii) $\mathrm{Ar}-\mathrm{X}(\mathrm{X}=\mathrm{Cl}$ or $\mathrm{Br}), \mathrm{K}_{2} \mathrm{CO}_{3}, \mathrm{Pd}\left(\mathrm{PPh}_{3}\right)_{4}$, tetrahydrofuran, water, reflux.

\subsection{Computational Simulations and Photophysical Properties}

To figure out the implication and discrepancy of various peripheral EWG substituents on the geometrical and electronic characteristics, the ground-state $\left(\mathrm{S}_{0}\right)$ geometries were initially optimized by utilizing density functional theory (DFT), and the geometrical configurations of the $\mathrm{S}_{1}$ states were simulated using time-dependent DFT (TDDFT). The HOMO/LUMO distributions, energy band gaps $\left(E_{\text {gap }}\right)$, oscillator strengths and electrostatic potential (ESP) distributions are illustrated in Figure 2. The 
HOMOs of four compounds are approximately identical to that of the parent molecule, which mainly distribute on the nitrogen atoms and the carbon atoms at its ortho/para positions in DtCzB moiety, whereas the LUMOs are predominantly localized on the boron atom and the carbon atoms at its ortho/para positions in the vicinity of DtCzB moiety, and partially extend to the appended EWG moiety to various extents. Assisted by the ESP analysis, the LUMO energy levels of four compounds are significantly pulled down by the partial negative potential induced by EWGs, which are evident for narrowed $E_{\text {gaps }}$ and thus red-shift emission. The reduction in the oscillator strengths of the investigated compounds, as compared to the parent molecule, is attributed to the enhanced ICT property. However, the oscillator strength values still maintain at high levels, facilitating high PLQYs. Intriguingly, when triazine moiety bonds directly to DtCzB core, the intramolecular hydrogen bonds $(\mathrm{C}-\mathrm{H} \cdots \mathrm{N})$ are induced, and DPTRZ moiety and DtCzB core are interlocked ogether (Figures S7). ${ }^{[8]}$ Consequently, the molecule DtCzB-DPTRZ displays a nearly planar structure based on the double intramolecular hydrogen bonds between DPTRZ segment and DtCzB core. The other three molecules (DtCzB-TPTRZ, DtCzB-PPm and DtCzB-CNPm) without intramolecular hydrogen bond exhibit distorted molecular configurations and large dihedral angles $(\theta)$ of around $37^{\circ}$ between EWG moieties and $\mathrm{DtCzB}$ core in the ground state. For molecule DtCzB-DPTRZ, the optimized $\mathrm{S}_{0}$ and $\mathrm{S}_{1}$ have very similar configurations, and the dihedral angles are close to each other, suggesting a minimum structural deformation upon switching between $S_{0}$ and $S_{1}$ states. For other three molecules, $\mathrm{S}_{0}$ and $\mathrm{S}_{1}$ show obviously different configurations and dihedral angles, 
directing the relatively significant structural deformation upon transforming between $\mathrm{S}_{0}$ and $\mathrm{S}_{1}$ states.

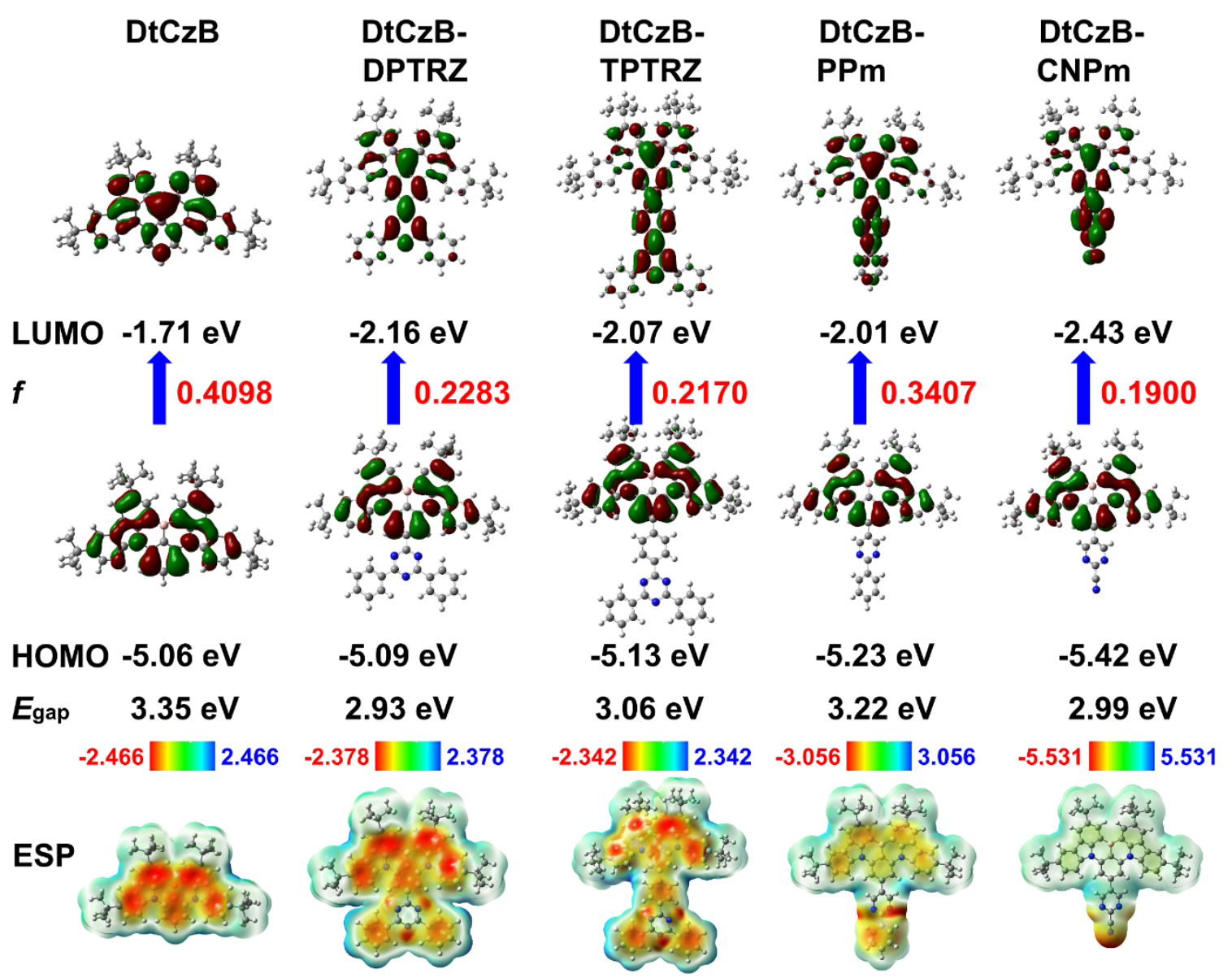

Figure 2. Calculated HOMO and LUMO distributions, energy band gaps, oscillator strengths and molecular surface electrostatic potential in $\mathrm{S}_{0}$ geometries of the investigated compounds (measuring scale $\times 10^{-2}$, red and blue indicate negative and positive electrostatic potential).

To understand the geometrical deformation quantitatively, the reorganization energies $(\lambda)$ are calculated according to the Marcus theory, which are closely associated with the excitation and emission processes and have a significant impact on the emission spectral profile. After the Franck-Condon vertical absorption transition, the internal conversion and vibrational relaxation lead to the geometrical deformation of the molecule and then relax to the emission state, which obeys the Kasha's rule: the photons must be emitted from the lowest-lying singlet or triplet excited states of the 
molecules with spin multiplicity and independent on excitation wavelength. ${ }^{[9]}$ In principle, the smaller reorganization energies are the prerequisites of generating small Stokes shift and narrowband emission. As depicted in Figure 3, the reorganization energies were calculated to be $0.16,0.22,0.17$ and $0.33 \mathrm{eV}$ for DtCzB-DPTRZ, DtCzBTPTRZ, DtCzB-PPm and DtCzB-CNPm, respectively, which are larger than that of DtCzB $(0.13 \mathrm{eV})$ (Figure S8), but still relatively small. The above theoretical calculation results reveal that the EWG substituents have limited influnce on the parent skeleton in terms of the frontier molecular orbitals distributions and reorganization energies. Therefore, it is reasonable to conjecture that the newly-constructed compounds should have narrowband emission. The four molecules attached with acceptors may inherit the original "fingerprint" features of DtCzB and have the MR gene. According to the decomposition results of reorganization energies from $\mathrm{S}_{1}$ to $\mathrm{S}_{0}$ depicted in Figure S9, it is clear that the representative normal vibration modes with large contribution to reorganization energies are dominantly located in the lowfrequency region $\left(<100 \mathrm{~cm}^{-1}\right)$ for DtCzB-TPTRZ, DtCzB-PPm and DtCzB-CNPm. The large reorganization energies mainly stem from the distinct out-of-plane bending vibration of molecular skeleton and particularly the vibration of EWG moiety (Figure S10), and the internal rotation between EWG moiety and DtCzB core (Figures S7). The enhanced low-frequency and suppressed high-frequency vibronic coupling are conducive to narrow FWHM. ${ }^{[10]}$ For DtCzB-DPTRZ, the representative normal vibration modes with large contribution to reorganization energies are nearly distributed in all-frequency region but with extremely small values of fragmented 
reorganization energies $\left(<20 \mathrm{~cm}^{-1}\right)$ due to the whole large rigid planar structures. The stretching vibrations of $\mathrm{DtCzB}$ core and triazine ring are observed in the high-frequency mode $\left(788 \mathrm{~cm}^{-1}\right)$, which may lead to the generation of shoulder peak (vibronic emission band) in the emission spectrum. It can be concluded that the reorganization energies of the excitation and emission process can be reduced by restricting the structural deformation between the ground and excited states, ${ }^{[11]}$ which may impart narrowband emission to TADF molecules eventually.

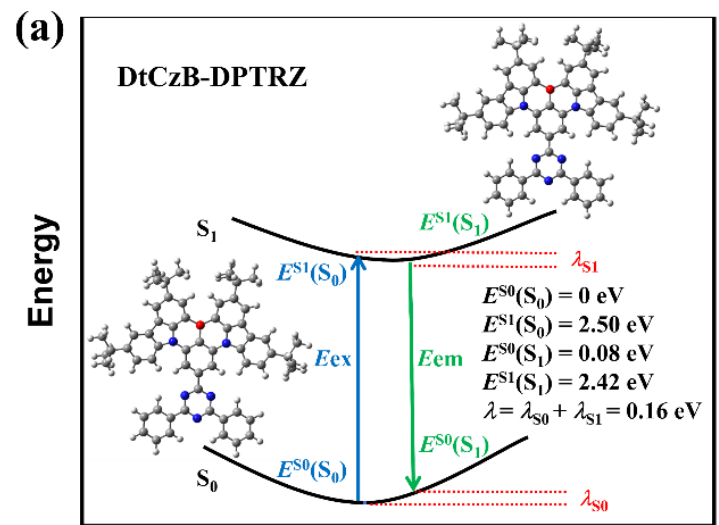

Geometry

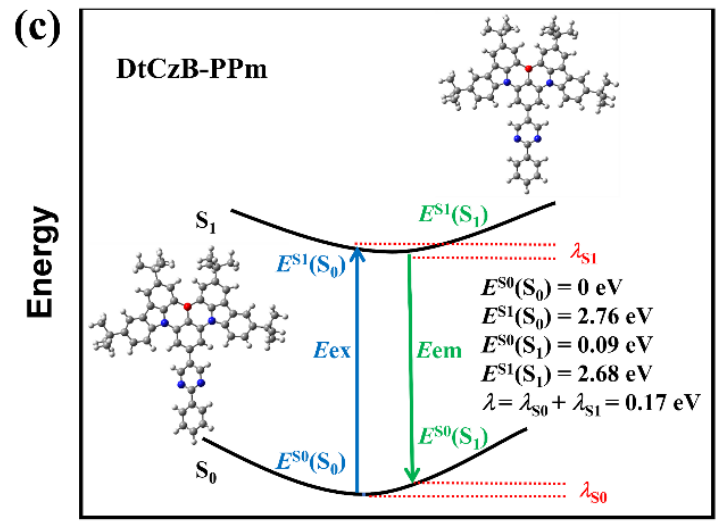

Geometry

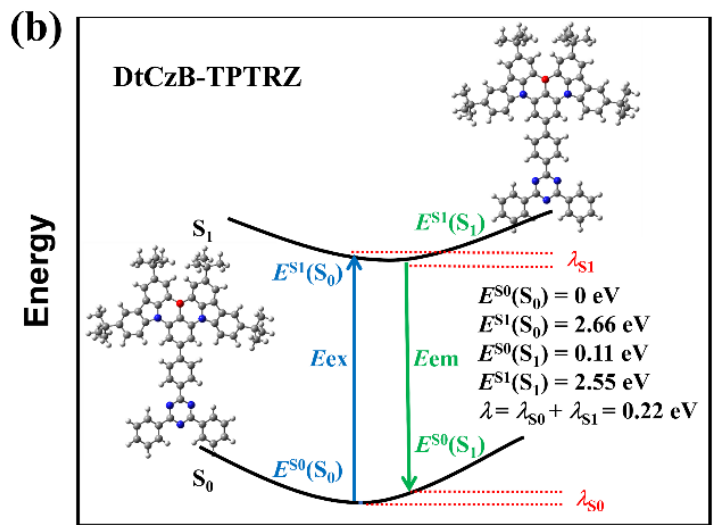

Geometry

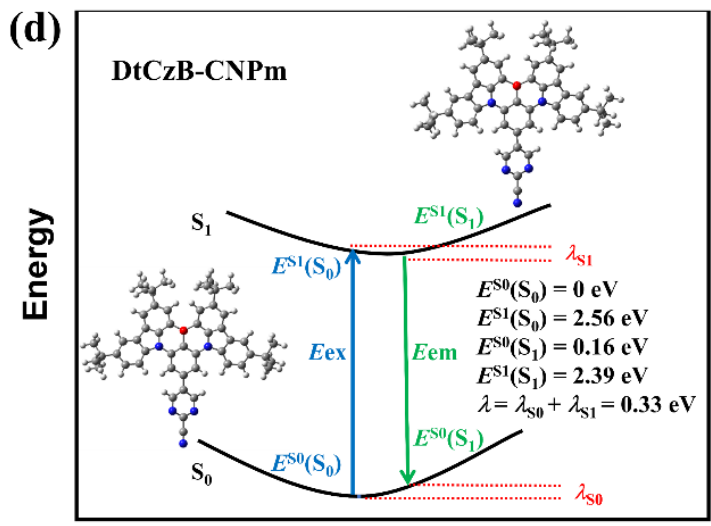

Geometry

Figure 3. Optimized $S_{0}$ and $S_{1}$ structures, single point energies and reorganization energies $(\lambda)$ of DtCzB-DPTRZ (a), DtCzB-TPTRZ (b), DtCzB-PPm (c) and DtCzBCNPm (d).

The preliminary photophysical properties of four compounds consisting of ultraviolet-visible (UV-vis) absorption and photoluminescence (PL) spectra were 
recorded in dilute toluene solution $\left(1 \times 10^{-5} \mathrm{M}\right)$. As depicted in Figure 4 and Table 1, the electronic absorption spectra display an intense absorption band peaking at 507, 477, 474 and $481 \mathrm{~nm}$ for DtCzB-DPTRZ, DtCzB-TPTRZ, DtCzB-PPm and DtCzB-CNPm, respectively, which are corresponding to the ICT absorption transitions. They all exhibit perfect green fluorescence with emission peaks at 521, 501, 499 and $515 \mathrm{~nm}$, small Stokes shifts of 14, 24, 25 and $34 \mathrm{~nm}$, and narrow FWHMs of 24, 27, 25 and 36 $\mathrm{nm}$, respectively. Additionally, they show positive solvatochromism and solventdependent spectral profile features, thereby confirming the typical ICT characteristic (Figure S11 and Table S1), which are well consistent with the theoretically calculated results. For DtCzB-DPTRZ, the formation of intramolecular hydrogen bond between triazine moiety and $\mathrm{DtCzB}$ core flattens the whole molecular framework and results in enhanced $\pi$-conjugation and ICT state, rendering the emission red-shift substantially in comparison with DtCzB. Simultaneously, the emission spectrum exhibits a small FWHM, accompanied with an appreciable shoulder peak that has significant influence on color purity, which originates from the high-frequency vibronic coupling corresponding to the large molecular conjugated plane. To eliminate the shoulder peak, the phenyl bridge was introduced into DtCzB-TPTRZ to elude the direct connection between triazine moiety and DtCzB core, which destroyed the intramolecular hydrogen bond interaction. Consequently, the $\pi$-conjugation of DtCzB-TDPTRZ was contracted and the rigidity of the whole molecular skeleton decreased, leading to hypsochromic shift of emission. As anticipated, the emission shoulder is largely removed, which is beneficial to the realization of green emission with high color purity, also clearly 
confirming that too large conjugated plane tends to generate shoulder peak. To further probe into the influence of the acceptor substitution on photophysical properties of MRtype TADF materials, another category of acceptor (pyrimidine) with different electron withdrawing ability was selected to replace triazine group. DtCzB-PPm has a tiny redshift emission in comparison with DtCzB due to the weak ICT state. To further advance the red-shift emission to longer wavelength region, the phenyl was replaced by cyano group and the ICT state increased dramatically. DtCzB-CNPm exhibits high-lying LUMO energy level, more dispersed ESP distribution and the strongest solvatochromism effect, leading to large molecular reorganization energies and Stokes shift as well as relatively large FWHM. The above spectral information and theoretical calculation reveal the antagonistic relationship between ICT strength and FWHM, that is, the strong charge delocalization can indeed cause large red-shift emission but at the expense of increasing Stokes shift and expanding FWHM. In order to achieve red-shift emission and narrow FWHM simultaneously, it is necessary to strike a balance between ICT strength degree and rigidity of the whole molecule composed of MR and auxiliary acceptor moieties, meaning that both should be increased at the same time. Moreover, to avoid the emergence of shoulder peak and obtain perfect color purity, the circumspect adjustment of molecular structures such as the number of intramolecular hydrogen bond should be also taken into consideration. 
(a)

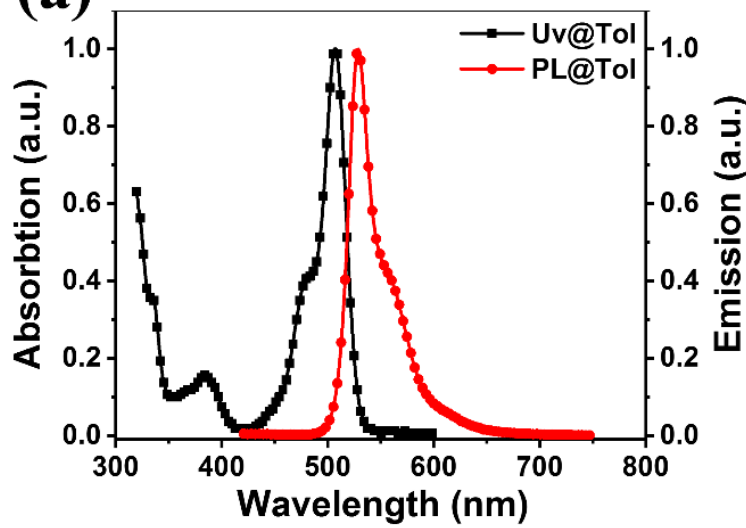

(c)

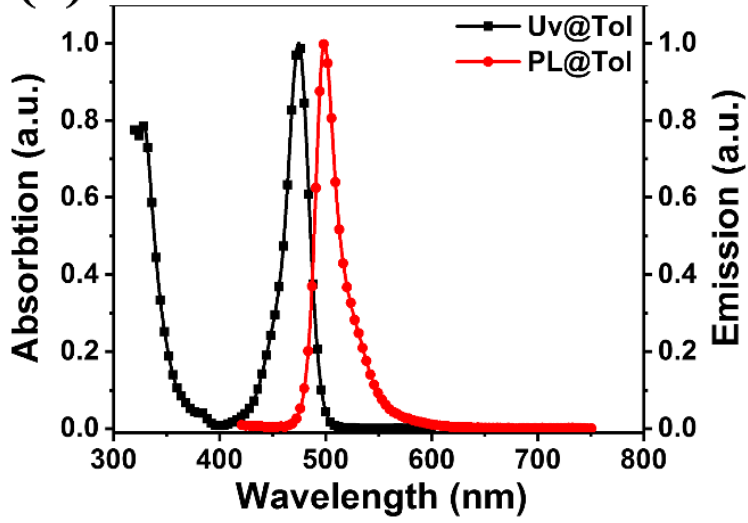

(b)

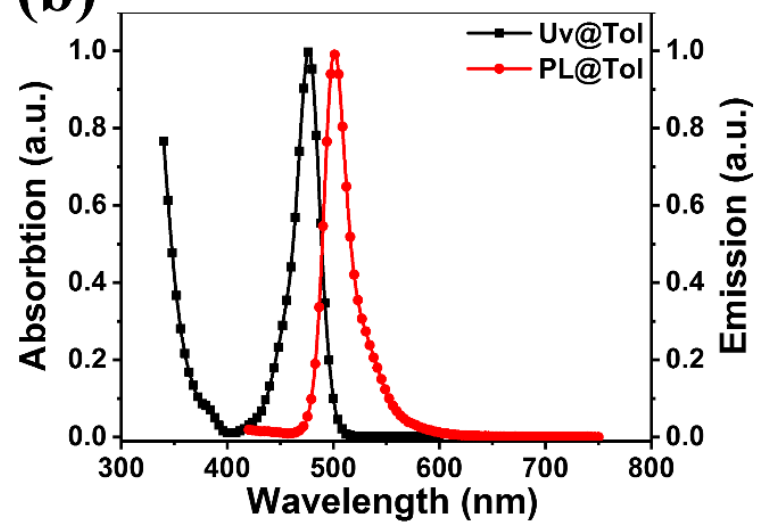

(d)

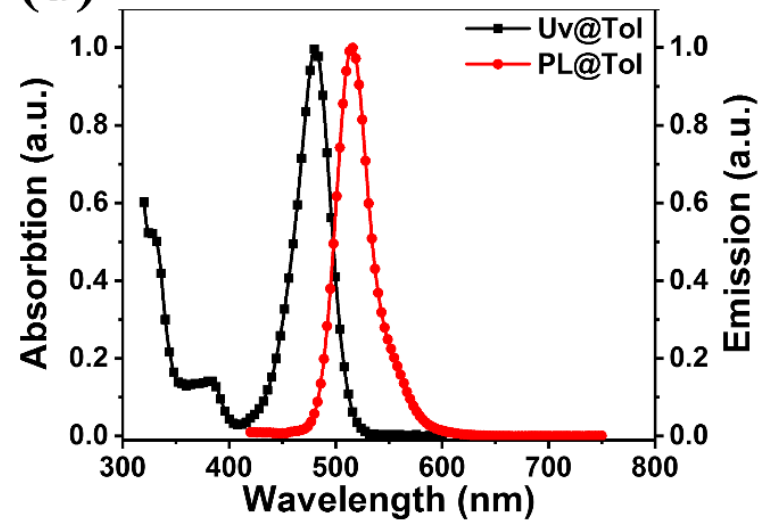

Figure 4. Normalized UV-vis absorption and fluorescence spectra of DtCzB-DPTRZ (a), DtCzB-TPTRZ (b), DtCzB-PPm (c) and DtCzB-CNPm (d) measured in toluene solution $\left(1 \times 10^{-5} \mathrm{M}, 298 \mathrm{~K}\right)$.

Table 1. Summary of the photophysical properties of the investigated compounds.

\begin{tabular}{lllllllllll}
\hline compound & $\begin{array}{l}\lambda_{\mathrm{abs}}{ }^{\mathrm{a})} \\
{[\mathrm{nm}]}\end{array}$ & $\begin{array}{l}\lambda_{\mathrm{em}}{ }^{\mathrm{b})} \\
{[\mathrm{nm}]}\end{array}$ & $\begin{array}{l}\left.\mathrm{FWHM}^{\mathrm{c}}\right) \\
{[\mathrm{nm}]}\end{array}$ & $\begin{array}{l}E_{\mathrm{S} 1}{ }^{\mathrm{d})} \\
{[\mathrm{eV}]}\end{array}$ & $\begin{array}{l}E_{\mathrm{T} 1}{ }^{\mathrm{e})} \\
{[\mathrm{eV}]}\end{array}$ & $\begin{array}{l}\Delta E_{\mathrm{ST}^{\mathrm{f}}} \\
{[\mathrm{eV}]}\end{array}$ & $\begin{array}{l}E_{\mathrm{g}}{ }^{\mathrm{g})} \\
{[\mathrm{eV}]}\end{array}$ & $\begin{array}{l}\mathrm{HOMO}^{\mathrm{h})} \\
{[\mathrm{eV}]}\end{array}$ & $\begin{array}{l}\mathrm{LUMO}^{\mathrm{i})} \\
{[\mathrm{eV}]}\end{array}$ & $\begin{array}{l}\Phi_{\mathrm{PL}}{ }^{\mathrm{j})} \\
{[\%]}\end{array}$ \\
\hline DtCZB-DPTRZ & 507 & 521 & 24 & 2.40 & 2.23 & 0.17 & 2.35 & -5.41 & -3.06 & 94 \\
DtCzB-TPTRZ & 477 & 501 & 27 & 2.54 & 2.43 & 0.11 & 2.48 & -5.32 & -2.84 & 97 \\
DtCzB-PPm & 474 & 499 & 25 & 2.50 & 2.42 & 0.08 & 2.51 & -5.35 & -2.84 & 96 \\
DtCzB-CNPm & 481 & 515 & 36 & 2.38 & 2.26 & 0.12 & 2.42 & -5.50 & -3.08 & 93 \\
\hline
\end{tabular}

a) The peak wavelength of the lowest-energy absorption band. ${ }^{\text {b) }}$ The peak wavelength of the PL spectrum in toluene $\left(1 \times 10^{-5} \mathrm{M}, 298 \mathrm{~K}\right){ }^{\mathrm{c}}{ }^{\mathrm{s}}$ Full width at half maximum. $\left.{ }^{\mathrm{d}}\right)$ Singlet energy estimated from the onset of the fluorescence spectrum in toluene $(1 \times$ $\left.10^{-5} \mathrm{M}, 77 \mathrm{~K}\right)$. e) Triplet energy estimated from the onset of the phosphorescence spectrum in a frozen toluene matrix $\left(1 \times 10^{-5} \mathrm{M}, 77 \mathrm{~K}\right) .{ }^{\mathrm{f})} \Delta E_{\mathrm{ST}}=E_{\mathrm{S} 1}-E_{\mathrm{T} 1 .}{ }^{\mathrm{g})}$ Optical band gap estimated from the absorption edge of UV-vis spectrum. ${ }^{\text {h) }}$ Determined from cyclic voltammetry by formula: $E_{\mathrm{HOMO}}=-\left(E_{\mathrm{ox}}+4.8\right) \mathrm{eV} .{ }^{\mathrm{i}}{ }$ Determined from formula: $E_{\mathrm{LUMO}}=E_{\mathrm{HOMO}}+E_{\mathrm{g} .}{ }^{\mathrm{j})}$ Absolute photoluminescence quantum yield measured with an integer-sphere system in $\mathrm{N}_{2}$-bubbling toluene. 
The absolute PLQYs of these compounds measured with an integer-sphere system in oxygen-free toluene solution are as high as 94\%, 97\%, 96\% and 93\%, respectively. Combined with the onsets of the low-temperature fluorescence and phosphorescence spectra at $77 \mathrm{~K}$ (Figure S12), the $\Delta E_{\mathrm{ST}}$ values were calculated to be $0.17,0.11,0.08$ and $0.12 \mathrm{eV}$, respectively. Such small $\Delta E_{\mathrm{ST}}$ values are conducive to exciton upconversion from $T_{1}$ to $S_{1}$ and thus give rise to TADF characteristic. To gain deeper insight into the emission property, the photophysical properties of these compounds in the doped thin films with $\mathrm{PhCzBCz}$ (9-(2-(9-phenyl-9H-carbazol-3-yl)phenyl)-9H-3,9'bicarbazole) as host (doped concentration of emitter: 3 wt $\%$ ) were studied comprehensively. Compared with the emission in low polar toluene solution, the doped films show vividly green emission with certain extent of red-shift, slightly broadened FWHM (Figure S13 and Table S2) and a little declined PLQY (Table S3), probably due to the aggregation induced emission quenching of the dopants in films. The transient PL decay spectra of the doped films show biexponential decays that are characterized by a prompt fluorescence decay with lifetime in the nanosecond regime and a delayed fluorescence component with lifetime in the microsecond regime (Figure S14). To determine the TADF nature of these compounds, the temperature-dependent transient PL spectra of the doped films were also recorded (Figure S15). Upon temperature increasing from 120 to $320 \mathrm{~K}$, the ratio of the delayed component from the recursive $\mathrm{S}_{1} \rightarrow \mathrm{S}_{0}$ transition through successive upconversion of triplet excitons enhances gradually, evidencing typical TADF characteristic. Notably, large prompt fluorescence rate constant $\left(k_{\mathrm{F}}\right)$ of these compounds are calculated as approximately $10^{7}$ 
order of magnitude (Table S3), which are higher value for TADF emitters. These features of TADF dyes are superior to the preparation of highly efficient OLED with perfect color purity.

\subsection{Electrochemical and Thermal Properties}

To study the electrochemical properties of the investigated compounds, the cyclic voltammetry (CV) measurements were carried out. These compounds show quasireversible oxidation process in the anodic scanning. Based on the oxidation onset potentials (Figure S16), the HOMO energy levels are determined to be -5.41, -5.32, 5.35 and -5.50 eV for DtCzB-DPTRZ, DtCzB-TPTRZ, DtCzB-PPm and DtCzBCNPm, respectively. The LUMO energy levels estimated by the optical bandgaps and the values are $-3.06,-2.84,-2.84$ and $-3.08 \mathrm{eV}$, respectively. For $\mathrm{DtCzB}$, the measured HOMO and LUMO energy levels are -5.40 and $-2.61 \mathrm{eV}$, respectively. The homologous HOMO and obviously decreased LUMO energy levels in comparison with that of DtCzB resemble well with the theoretically calculated values, indicating the subsequently bathochromic shift of emission. To check the thermal stability, thermogravimetric analysis (TGA) was adopted under nitrogen atmosphere. As depicted in Figure S17, sufficiently high decomposition temperatures $\left(>450{ }^{\circ} \mathrm{C}\right)$ are detected for these compounds, which support the vacuum thermal deposition process for OLED manufacturing.

\subsection{OLED Device Performance}

To evaluate the EL performances of four compounds, multilayer OLEDs with the optimized device configuration of [ITO/TAPC $(50 \mathrm{~nm}) / \mathrm{TCTA}(5 \mathrm{~nm}) / \mathrm{PhCzBCz}: 3 \mathrm{wt} \%$ 
the investigated compounds $(30 \mathrm{~nm}) / \mathrm{TmPyPB}(30 \mathrm{~nm}) / \mathrm{LiF}(1 \mathrm{~nm}) / \mathrm{Al}(100 \mathrm{~nm})]$ were fabricated initially. In devices $\mathrm{PhCzBCz}$ was designated as the host of the emitting layer (EML), TAPC (1,1-bis[(di-4-tolylamino)phenyl]cyclohexane) and TmPyPB (3,3'-[5'[3-(3-pyridinyl)phenyl][1,1':3',1"-terphenyl]-3,3"-diyl]bispyridine) were employed as the hole transporting layer (HTL) and electron transporting layer (ETL), respectively. To prevent exciton penetrating into TAPC layer, TCTA (tris(4-carbazolyl-9ylphenyl)amine) was adopted as the exciton confining layer (ECL). The energy level diagram of devices and molecular structures of used materials are showed in Figure S18. The EL spectra and other device performances related to efficiencies, current densities $(J)$, voltages $(V)$ and luminance $(L)$ are given in Figure S19, the detailed device parameters are compiled in Table $\mathbf{S 4}$.

The as-prepared devices exhibit green emission with the peaks at 532 (DtCzBDPTRZ), 516 (DtCzB-TPTRZ), 508 (DtCzB-PPm) and 540 nm (DtCzB-CNPm), respectively. As anticipated, narrow FWHMs of 39, 38, 33 and $44 \mathrm{~nm}$ and outstanding CIE coordinates of $(0.33,0.63),(0.18,0.67),(0.16,0.66)$ and $(0.35,0.63)$ are observed (Figure S20), respectively. The EL spectra of all devices match well with their corresponding PL spectra of the doped emitting layers. The emission of $\mathrm{PhCzBCz}$ disappears, indicating that the radiative transition excitons are well-confined on the dopants. Additionally, remarkable maximum EQE up to $24.6 \%, 29.8 \%, 28.6 \%$ and $25.0 \%$ are achieved for these devices, mainly benefiting from the high PLQYs of the doped emitting layers. The highly efficient narrowband green EL testifies the rationality of our molecular construction prominently, providing profound insight into molecular 
architectonics for achieving bathochromic shift and narrowband emission concurrently with the combination of our proposed synthetic strategy.

The relatively small rate constant of reverse intersystem crossing ( $\left.k_{\mathrm{RISC}}\right)$ of DtCzB$\operatorname{DPTRZ}\left(0.10 \times 10^{4} \mathrm{~s}^{-1}\right)$ and DtCzB-CNPm $\left(0.14 \times 10^{4} \mathrm{~s}^{-1}\right)$ can account for the steeper efficiency roll-off compared with that of DtCzB-TPTRZ $\left(1.08 \times 10^{4} \mathrm{~s}^{-1}\right)$ and DtCzBPPm $\left(1.02 \times 10^{4} \mathrm{~s}^{-1}\right)$. However, the efficiency roll-offs of the devices are all sharp, resulting from the sluggish triplet exciton dynamics of emitters invoked by severe bimolecular quenching events such as triplet-triplet annihilation (TTA) or tripletpolaron annihilation (TPA) at high brightness because of the long duration of delayed fluorescence. ${ }^{[12]}$ For real-world applications, it is essential to alleviate efficiency rolloff and warrant high device efficiency under high luminance. ${ }^{[13]}$ Therefore, it is paramount to optimize the EL performance of these devices and suppress the efficiency attenuation at high brightness, which immensely demands the systematical management of the host to decrease the leakage of triplet exciton. An alternative route for triplet exciton harvesting is to adopt TADF molecules as an assistant dopant in OLED by optimizing energy transfer process. ${ }^{[14]}$ It is well-documented that the typical double-doped OLED is comprised of a wide-energy-gap host, a TADF-assistant dopant and a fluorescent dye. In this system, triplet excitons generated on a TADF-assistant dopant by electrical excitation are repopulated on the $S_{1}$ state of that, and then entirely transferred to the $S_{1}$ state of fluorescent emitter via long-range Förster energy transfer (FET) process, which facilitates exciton utilization efficiency and produces efficient radiative decay from $\mathrm{S}_{1}$ state of the fluorescent emitter. Recently, OLEDs utilizing this 
cascade energy transfer mechanism have attracted tremendous attention. TADFassistant dopant with fast RISC rate from $T_{1}$ to $S_{1}$ state can efficiently suppress shortrange Dexter energy transfer (DET) process and thus reduce exciton wastage induced by annihilation. Based on the fundamental principles, we elaborately screened a sterically shielded sky blue TADF material-2,3,4,5,6-pentakis-(3,6-di-tert-butyl-9Hcarbazol-9-yl)benzonitrile (5tBuCzBN) (HOMO: -5.45 eV, LUMO: $-2.74 \mathrm{eV}$ ) as a TADF-assistant dopant, which features the figure-of-merits of large $k_{\mathrm{RISC}}\left(1.81 \times 10^{5}\right.$ $\mathrm{s}^{-1}$ ) and high PLQY (86\%). ${ }^{[15]}$ More importantly, the large spectral overlap between emission wavelength of $5 \mathrm{tBuCzBN}$ and the absorption wavelength range of the investigated compounds can guarantee efficient FET process (Figure S21). The introduction of TADF-assistant dopant can remarkably increase the singlet exciton:triplet exciton ratio of the fluorescent dye, so that alleviation of efficiency rolloff can be expected.

In view of the above analysis, the OLEDs with the structure of [ITO/TAPC (50 $\mathrm{nm}) / \mathrm{TCTA}(5 \mathrm{~nm}) / \mathrm{PhCzBCz}: 15 \mathrm{wt} \%$ tBuCzBN:x wt $\%$ the investigated compounds $(30 \mathrm{~nm}) / \mathrm{TmPyPB}(30 \mathrm{~nm}) / \operatorname{LiF}(1 \mathrm{~nm}) / \mathrm{Al}(100 \mathrm{~nm})](\mathrm{x}=3,5,10)$ were fabricated. The variable doping concentrations of the investigated compounds were implemented for modulating the device performances. The EL spectra, EQE $-L, J-V-L$, current efficiency $(\mathrm{CE})$ and power efficiency (PE) versus $L$ curves are shown in Figures 5 and Figure S22, and the device parameters are listed in Table 2 and Table S5. Clearly, the most intuitive consequence is that all devices based on the investigated compounds with the introduction of $5 \mathrm{tBuCzBN}$-assistant dopant can be indeed capable of achieving high 
EQEs and lower efficiency roll-offs. With the increase of doping concentration, the efficiency roll-off becomes more serious, the most reasonable explanation for this phenomenon is that two competitive excited state energy consumption pathways, including direct charge trapping on the emitter and the DET channel unlocking from the triplet of $5 \mathrm{tBuCzBN}$ matrix to that of emitter in the high doping concentration circumstance (Figure S23), may be released, resulting in the energy loss of triplet excitons.

For DtCzB-DPTRZ-based emitter, the devices show incomplete energy transfer with the appearance of additional EL components in the blue region, due to the minimum spectral overlap between emission spectrum of $5 \mathrm{tBuCzBN}$ and the maximum absorption band of DtCzB-DPTRZ among four compounds that brings about an inefficient FET process (Figure S21). This phenomenon may be eliminated by elaborately selecting more suitable TADF-assistant dopant and the overall EL performance of devices may be further improved. For DtCzB-TPTRZ-based emitter, the best EL performance is achieved at $5 \mathrm{wt} \%$ doping concentration with the maximum EQE, CE and PE up to $30.6 \%, 105.8 \mathrm{~cd} \mathrm{~A}^{-1}$ and $116.2 \mathrm{~lm} \mathrm{~W}^{-1}$, respectively, which is comparable to the that of phosphorescence-based green OLEDs. ${ }^{[16]}$ Simultaneously, the device exhibits pure green emission with CIE coordinates of $(0.23,0.68)$, which extremely assembles the standard green-light CIE coordinates of $(0.21,0.71)$ stipulated by the NTSC (Figure S24). Regarding the overall EL performance, the device represents the state-of-the-art green emitter among the TADF materials reported to date. ${ }^{[2 \mathrm{~g}-\mathrm{h}, 6 \mathrm{i}-\mathrm{n}]}$ In addition, the device exhibits good spectra stability over a wide range of 
operating voltages from 3 to 8 V (Figure S25). The DtCzB-PPm-based devices display pure green emission and the device with $5 \mathrm{wt} \%$ doping concentration exhibits the optimized maximum EQE, CE and PE up to $29.8 \%, 93.3 \mathrm{~cd} \mathrm{~A}^{-1}$ and $103.31 \mathrm{~m} \mathrm{~W}^{-1}$, respectively. Notably, the EQE maintains a high value of $21.7 \%$ at high luminance of $1000 \mathrm{~cd} \mathrm{~m}^{-2}$ and the corresponding spectrum is peaking at $508 \mathrm{~nm}$ with narrow FWHM of $35 \mathrm{~nm}$, thus realizing excellent color purity with CIE coordinates of $(0.17,0.67)$. For DtCzB-CNPm-based emitter, the devices show yellowish green emission with maximum wavelength of $540 \mathrm{~nm}$ and FWHM of $44 \mathrm{~nm}$. The device with $3 \mathrm{wt} \%$ doping concentration displays the highest maximum EQE, CE and PE up to 28.1\%, $102.1 \mathrm{~cd}$ $\mathrm{A}^{-1}$ and $114.5 \mathrm{~lm} \mathrm{~W}^{-1}$, respectively. To sum up, we have achieved outstanding device performances by modulating the emitter and regulating the device configuration, nevertheless, the enhancement of ICT characteristic can induce extension of FWHM after introducing TADF-assistant dopant. Further optimizations of the host, TADFassistant dopant and device architecture may result in the EL spectra with desired FWHM values.

Table 2. Summary of the EL data of the DtCzB-TPTRZ-based devices with 5 tBuCzBN-assistant dopant.

\begin{tabular}{|c|c|c|c|c|c|c|c|c|}
\hline $\mathrm{xwt} \%$ & $\begin{array}{l}\lambda_{\mathrm{em}^{\mathrm{a}}} \\
{[\mathrm{nm}]}\end{array}$ & $\begin{array}{c}\text { FWHM }^{\text {b) }} \\
{[\mathrm{nm}]}\end{array}$ & $\begin{array}{l}V_{\mathrm{on}}^{\mathrm{c})} \\
{[\mathrm{V}]}\end{array}$ & $\begin{array}{c}L_{\max }{ }^{\mathrm{d})} \\
{\left[\mathrm{cd} \mathrm{m}^{-2}\right]}\end{array}$ & $\begin{array}{c}\mathrm{CE}_{\max }^{\mathrm{e})} \\
{\left[\mathrm{cd} \mathrm{A}^{-1}\right]}\end{array}$ & $\begin{array}{c}\left.\mathrm{PE}_{\max }{ }^{\mathrm{f}}\right) \\
{\left[\operatorname{lm} \mathrm{W}^{-1}\right]}\end{array}$ & $\begin{array}{c}\mathrm{EQE}^{\mathrm{g})} \\
{[\%]} \\
\end{array}$ & $\operatorname{CIE}(x, y)^{h)}$ \\
\hline 3 & 516 & 40 & 2.9 & 20830 & 88.0 & 95.3 & $28.0 / 26.2 / 15.0$ & $(0.20,0.67)$ \\
\hline 5 & 520 & 41 & 2.8 & 25520 & 105.8 & 116.2 & $30.6 / 28.6 / 16.4$ & $(0.23,0.68)$ \\
\hline 10 & 520 & 44 & 2.8 & 21760 & 101.6 & 114.0 & $29.0 / 26.4 / 12.6$ & $(0.25,0.68)$ \\
\hline & $\begin{array}{l}\text { EL p } \\
\text { Maxim } \\
\text { Maxim }\end{array}$ & wavelen & b) $\mathrm{Fu}$ & idth at he & naximum & $\begin{array}{l}\text { Turn-on } \\
\text { Maximu } \\
0 \text { and } 10\end{array}$ & $\begin{array}{l}\text { oltage at } 1 \mathrm{~cd} \mathrm{n} \\
\text { power efficier } \\
\mathrm{cd} \mathrm{m}^{-2}, \text { respec }\end{array}$ & $\begin{array}{l}-2 \text { d) } \\
y . \text { g) } \\
\text { vely. }\end{array}$ \\
\hline
\end{tabular}




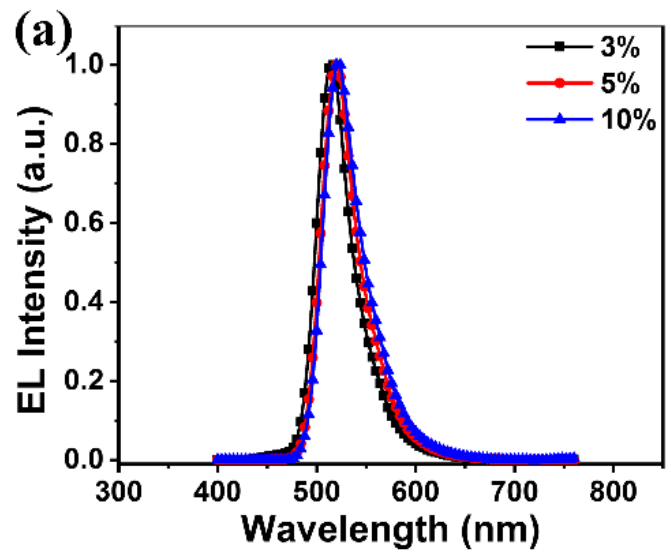

(c)

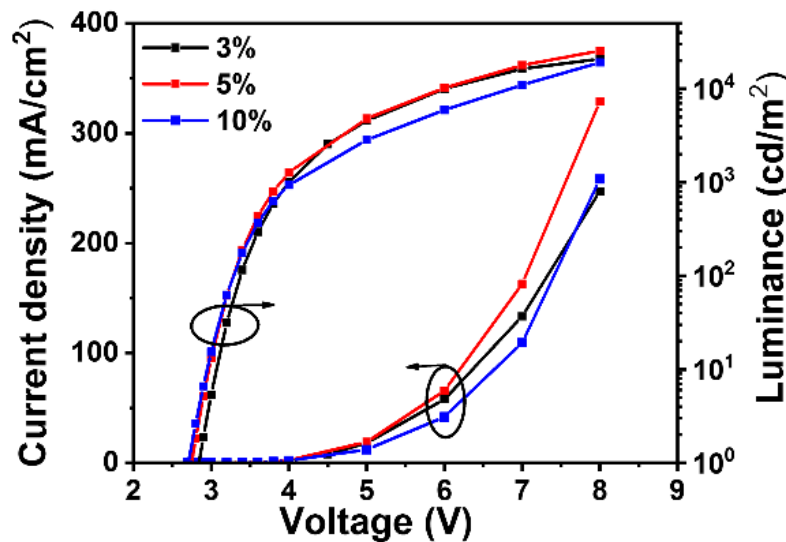

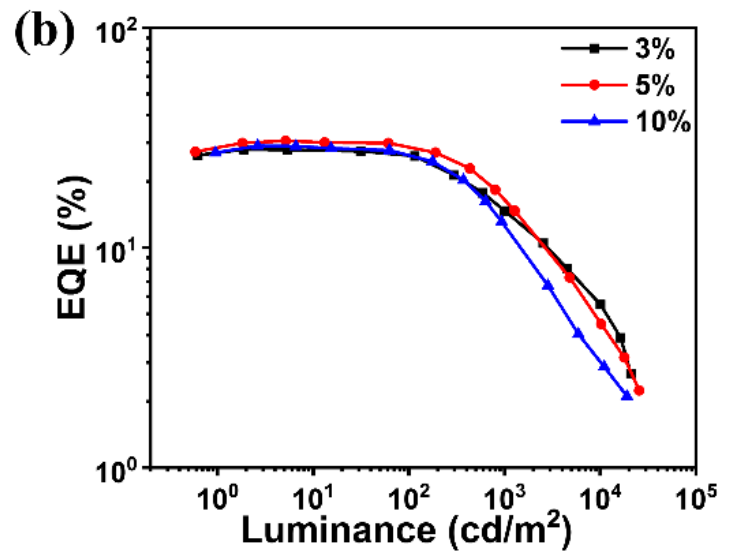

(d)

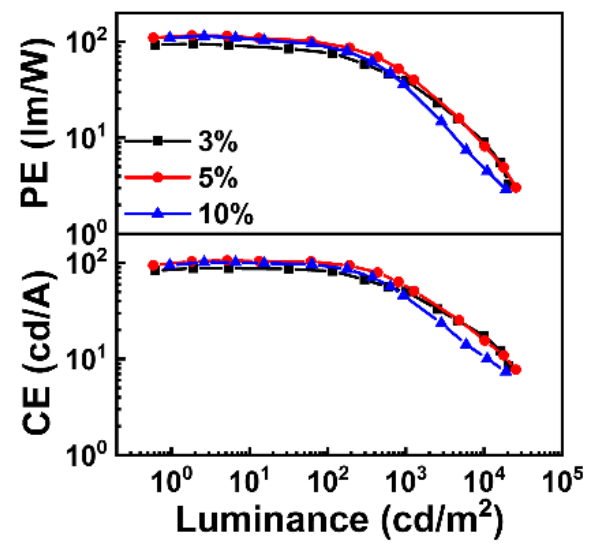

Figure 5. The EL characteristics of the devices with the configuration of [ITO/TAPC $(50 \mathrm{~nm}) /$ TCTA $(5 \mathrm{~nm}) / \mathrm{PhCzBCz}: 15 \mathrm{wt} \%$ 5tBuCzBN: $\mathrm{x}$ wt $\%$ DtCzB-TPTRZ (30 $\mathrm{nm}) / \operatorname{TmPyPB}(30 \mathrm{~nm}) / \mathrm{LiF}(1 \mathrm{~nm}) / \mathrm{Al}(100 \mathrm{~nm})](\mathrm{x}=3,5,10)$. (a) EL spectra. (b) EQE$L$ curves. (c) $J-V-L$ curves. (d) CE- $L$ and PE- $L$ curves.

\section{Conclusion}

In conclusion, we have developed an efficient synthetic methodology to functionalize MR framework and attached strong auxiliary electron acceptor onto the para-carbon position of B-substituted phenyl-ring, leading to the formation of MR and D-A complex type ICT molecules with TADF characteristic. For this class composite molecules, the excited state energy can be easily reduced by lowering LUMO energy level, resulting in longer wavelength emission molecules that preserve narrowband emission. We provide a straightforward and effective approach to construct emissive materials with desirable color purity in longer wavelength region for the fabrication of 
high-performance OLEDs. In this study, we present a finely modulated molecule DtCzB-TPTRZ with 1,3,5-triazine-based auxiliary acceptor, which exhibits ultrapure green EL with CIE coordinates of $(0.23,0.68)$ and maximum EQE of $30.6 \%$ as well as lower efficiency roll-off. The crucial substance to these unprecedented results is the perfect combination of inherent advantages consisting of MR skeleton and D-A configuration. More importantly, the synthetic method is simple, direct and feasible. The strategy reported in this study can be widely applied in the modification of B-Ncontaining MR framework with universal substituents such as donor, acceptor and moieties without obvious electron push-pull characteristics. This approach provides a platform for exploring a wide range of B-N-containing molecules, thus accelerating the vigorous development of narrowband emitters in the future.

\section{Acknowledgements}

This work was supported by the National Natural Science Foundation of China (21935005 and 51803069) and the National Key R\&D Program of China (2020YFA0714601).

\section{Conflict of Interest}

The authors declare no conflict of interest. 


\section{References}

[1] a) H. Uoyama, K. Goushi, K. Shizu, H. Nomura, C. Adachi, Nature 2012, 492, 234-238; b) C. W. Tang, S. A. VanSlyke, Appl. Phys. Lett. 1987, 51, 913-915; c) Y.

Tao, K. Yuan, T. Chen, P. Xu, H. Li, R. Chen, C. Zheng, L. Zhang, W. Huang, Adv. Mater. 2014, 26, 7931-7958; d) Z. Yang, Z. Mao, Z. Xie, Y. Zhang, S. Liu, J. Zhao, J. Xu, Z. Chi, M. P. Aldred, Chem. Soc. Rev. 2017, 46, 915-1016.

[2] a) J. W. Sun, J.-H. Lee, C.-K. Moon, K.-H. Kim, H. Shin, J.-J. Kim, Adv. Mater. 2014, 26, 5684-5688; b) P. L. Dos Santos, J. S. Ward, D. G. Congrave, A. S. Batsanov, J. Eng, J. E. Stacey, T. J. Penfold, A. P. Monkman, M. R. Bryce, Adv. Sci. 2018, 5, 1700989; c) K. Wu, T. Zhang, Z. Wang, L. Wang, L. Zhan, S. Gong, C. Zhong, Z. H. Lu, S. Zhang, C. Yang, J. Am. Chem. Soc. 2018, 140, 8877-8886; d) J. Huang, H. Nie, J. Zeng, Z. Zhuang, S. Gan, Y. Cai, J. Guo, S. J. Su, Z. Zhao, B. Z. Tang, Angew. Chem. Int. Ed. 2017, 56, 12971-12976; Angew. Chem. 2017, 129, 13151-13156; e) X.-K. Chen, Y. Tsuchiya, Y. Ishikawa, C. Zhong, C. Adachi, J.-L. Brédas, Adv. Mater. 2017, 29, 1702767; f) X. Y. Cai, S.-J. Su, Adv. Funct. Mater. 2018, 28, 1802558; g) P. Rajamalli, N. Senthilkumar, P. Gandeepan, P. Y. Huang, M. J. Huang, C. Z. Ren - Wu, C. Y. Yang, M. J. Chiu, L. K. Chu, H. W. Lin, C. H. Cheng, J. Am. Chem. Soc. 2016, 138, 628 - 634; h) T.-L. Wu, M.-J. Huang, C.-C. Lin, P.-Y. Huang, T.-Y. Chou, R.-W. Chen-Cheng, H.-W. Lin, R.-S. Liu, C.-H. Cheng, Nat. Photonics 2018, 12, 235-240.

[3] F. Santoro, A. Lami, R. Improta, J. Bloino, V. Barone, J. Chem. Phys. 2008, 128, 224311. 
[4] a) X. Li, Y. Z. Shi, K. Wang, M. Zhang, C. J. Zheng, D. M. Sun, G. L. Dai, X. C. Fan, D. Q. Wang, W. Liu, Y. Q. Li, J. Yu, X. M. Ou, C. Adachi, X. H. Zhang, ACS Appl. Mater. Interfaces 2019, 11, 13472-13480; b) Y. Yuan, X. Tang, X. Y. Du, Y. Hu, Y. J. Yu, Z. Q. Jiang, L. S. Liao, S. T. Lee, Adv. Opt. Mater. 2019, 7, 1801536; c) D. Hall, S. M. Suresh, P. L. dos Santos, E. Duda, S. Bagnich, A. Pershin, P. Rajamalli, D. B. Cordes, A. M. Z. Slawin, D. Beljonne, A. Köhler, I. D. W. Samuel, Y. Olivier, E. Zysman - Colman, Adv. Opt. Mater. 2020, 8, 1901627.

[5] a) T.-Y. Cho, C.-L. Lin, C.-C. Wu, Appl. Phys. Lett. 2006, 88, 111106; b) D. Poitras, C.-C. Kuo, C. Py, Opt. Express 2008, 16, 8003-8015; c) N. Takada, T. Tsutsui, S. Saito, Appl. Phys. Lett. 1993, 63, 2032.

[6] a) T. Hatakeyama, K. Shiren, K. Nakajima, S. Nomura, S. Nakatsuka, K. Kinoshita, J. Ni, Y. Ono, T. Ikuta, Adv. Mater. 2016, 28, 2777-2781; b) Y. Kondo, K. Yoshiura, S. Kitera, H. Nishi, S. Oda, H. Gotoh, Y. Sasada, M. Yanai, T. Hatakeyama, Nat. Photonics 2019, 13, 678-682; c) S. H. Han, J. H. Jeong, J. W. Yoo, J. Y. Lee, J. Mater. Chem. C 2019, 7, 3082-3089; d) K. H. Lee, J. Y. Lee, J. Mater. Chem. C 2019, 7, 85628568; e) J. A. Knoller, G. Meng, X. Wang, D. Hall, A. Pershin, D. Beljonne, Y. Olivier, S. Laschat, E. Zysman-Colman, S. Wang, Angew. Chem. Int. Ed. 2020, 59, 3156-3160; Angew. Chem. 2020, 132, 3181-3185; f) S. Oda, B. Kawakami, R. Kawasumi, R. Okita, T. Hatakeyama, Org. Lett. 2019, 21, 9311-9314; g) K. Matsui, S. Oda, K. Yoshiura, K. Nakajima, N. Yasuda, T. Hatakeyama, J. Am. Chem. Soc. 2018, 140, 1195-1198; h) S. Nakatsuka, H. Gotoh, K. Kinoshita, N. Yasuda, T. Hatakeyama, Angew. Chem. Int. Ed. 2017, 56, 5087-5090; Angew. Chem. 2017, 129, 5169-5172; i) Y. Zhang, D. Zhang, J. 
Wei, Z. Liu, Y. Lu, L. Duan, Angew. Chem. Int. Ed. 2019, 58, 16912-16917; Angew. Chem. 2019, 131, 17068-17073; j) Y. Xu, Z. Cheng, Z. Li, B. Liang, J. Wang, J. Wei, Z. Zhang, Y. Wang, Adv. Opt. Mater. 2020, 8, 1902142; k) Y. Xu, C. Li, Z. Li, Q. Wang, X. Cai, J. Wei, Y. Wang, Angew. Chem. Int. Ed. 2020, 59, 17442-17446; Angew. Chem. 2020, 132, 17595-17599; 1) Y. Zhang, D. Zhang, J. Wei, X. Hong, Y. Lu, D. Hu, G. Li, Z. Liu, Y. Chen, L. Duan, Angew. Chem. Int. Ed. 2020, 59, 17499-17503; Angew. Chem. 2020, 132, 17652-17656; m) N. Ikeda, S. Oda, R. Matsumoto, M. Yoshioka, D. Fukushima, K. Yoshiura, N. Yasuda, T. Hatakeyama, Adv. Mater. 2020, 32, 2004072; n) M. Yang, I. S. Park, T. Yasuda, J. Am. Chem. Soc. 2020, 142, $19468-$ 19472; o) S. Oda, W. Kumano, T. Hama, R. Kawasumi, K. Yoshiura, T. Hatakeyama, Angew. Chem. Int. Ed. 2021, 60, 2882-2886; Angew. Chem. 2021, 133, 2918-2922.

[7] A. K. Narsaria, F. Rauch, J. Krebs, P. Endres, A. Friedrich, I. Krummenacher, H. Braunschweig, M. Finze, J. Nitsch, F. M. Bickelhaupt, T. B. Marder, Adv. Funct. Mater. 2020, 30, 2002064.

[8] a) V. Thangaraji, P. Rajamalli, J. Jayakumar, M.-J. Huang, Y.-W. Chen, C.-H. Cheng, ACS Appl. Mater. Interfaces 2019, 11, 17128-17133; b) H.-J. Park, S. H. Han, J. Y. Lee, H. Han, E.-G. Kim, Chem. Mater. 2018, 30, 3215-3222.

[9] A. P. Demchenko, V. I. Tomin, P.-T. Chou, Chem. Rev. 2017, 117, 13353-1338.

[10]X. Qiu, G. Tian, C. Lin, Y. Pan, X. Ye, B. Wang, D. Ma, D. Hu, Y. Luo, Y. Ma, Adv. Opt. Mater. 2020, 2001845.

[11] I. S. Park, K. Matsuo, N. Aizawa, T. Yasuda, Adv. Funct. Mater. 2018, 28, 1802031. 
[12]C. Rothe, S. M. King, A. P. Monkman, Phys. Rev. Lett. 2006, 97, 076602.

[13]C. Murawski, K. Leo, M. C. Gather, Adv. Mater. 2013, 25, 6801-6827.

[14]a) H. Nakanotani, T. Higuchi, T. Furukawa, K. Masui, K. Morimoto, M. Numata, H. Tanaka, Y. Sagara, T. Yasuda, C. Adachi, Nat. Common. 2014, 5, 4016; b) S. Wang, Y. Zhang, W. Chen, J. Wei, Y. Liu, Y. Wang, Chem. Commun. 2015, 51, 11972-11975; c) D. Zhang, X. Song, M. Cai, and L. Duan, Adv. Mater. 2018, 30, 1705250; d) D. Zhang, X. Song, M. Cai, H. Kaji, L. Duan, Adv. Mater. 2018, 30, 1705406; e) D. Zhang, X. Song, A. J. Gillett, B. H. Drummond, S. T. E. Jones, G. Li, H. He, M. Cai, D. Credgington, L. Duan, Adv. Mater. 2020, 32, 1908355.

[15]D. D. Zhang, M. H. Cai, Y. G. Zhang, D. Q. Zhang, L. Duan, Mater. Horiz. 2016, $3,145-151$.

[16]a) C.-H. Shih, P. Rajamalli, C.-A. Wu, M.-J. Chiu, L.-K. Chu, C.-H. Cheng, J. Mater. Chem. C 2015, 3, 1491-1496; b) H.-H. Chou, C.-H. Cheng. Adv. Mater. 2010, $22,2468-2471$. 


\section{Table of contents}

A significant synthetic methodology has been proposed to functionalize multiple resonance framework and employed to produce a universal building block, which can be utilized to attach multifarious substituents and develop TADF materials with high color purity. The optimized DtCzB-TPTRZ-based OLED exhibits pure green emission with CIE coordinates of $(0.23,0.68)$ and maximum EQE of $30.6 \%$.

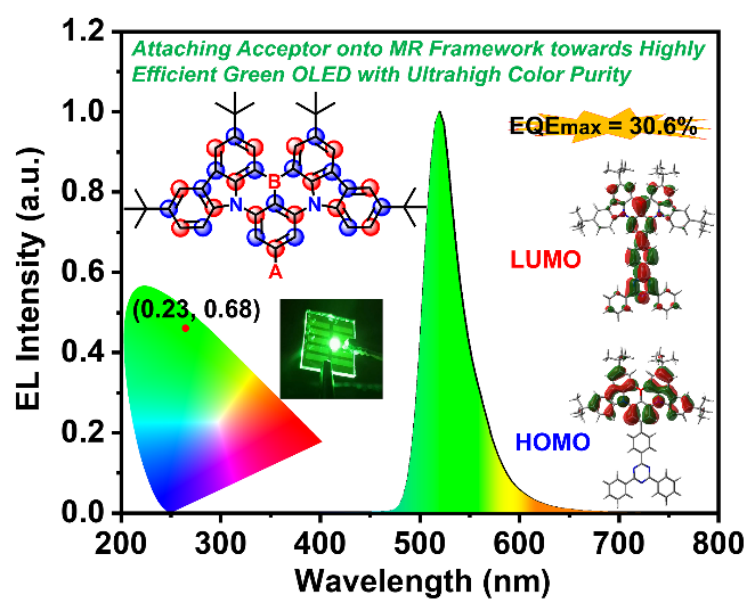




\section{Supporting Information}

General Information: Thermo Fisher ITQ1100 GC/MS mass spectrometer was employed to measure the mass spectra. Flash EA 1112 spectrometer were used to perform the elemental analyses. Bruker AVANCE III 500 and $600 \mathrm{MHz}$ spectrometers were selected to measure the ${ }^{1} \mathrm{H}$ and ${ }^{13} \mathrm{C}\left\{{ }^{1} \mathrm{H}\right\}$ NMR spectra, respectively, with tetramethylsilane (TMS) as the internal standard. Shimadzu RF-5301 PC spectrometer and Shimadzu UV-2550 spectrophotometer were adopted to record the PL emission spectra and UV-Vis absorption, respectively. The fluorescence and phosphorescent spectra taken at liquid nitrogen temperature $(77 \mathrm{~K})$ were recorded by Ocean Optics QE Pro with a $365 \mathrm{~nm}$ Ocean Optics LLS excitation source. Edinburgh FLS920 steady state fluorimeter equipping with an integrating sphere was employed to measure the absolute fluorescence quantum yields of both solutions and films. In the range of 25 to $800{ }^{\circ} \mathrm{C}$, TA Q500 thermogravimeter was selected to perform the thermogravimetric analysis (TGA) of target molecules under nitrogen atmosphere at a heating rate of $10 \mathrm{~K} \mathrm{~min}^{-1}$. BAS 100W Bioanalytical electrochemical work station was used to measure the electrochemical property with platinum disk as working electrode, platinum wire as auxiliary electrode, a porous glass wick $\mathrm{Ag} / \mathrm{Ag}^{+}$as pseudo reference electrode and ferrocene/ferrocenium as the internal standard. And $0.1 \mathrm{M}$ solution of $\mathrm{n}-\mathrm{Bu}_{4} \mathrm{NPF}_{6}$ which was the supporting electrolyte was utilized to measure the oxidation potentials (in anhydrous $\mathrm{CH}_{2} \mathrm{Cl}_{2}$ ) at a scan rate of $100 \mathrm{mV} \mathrm{s}^{-1}$. FLS980 fluorescence lifetime measurement system with $365 \mathrm{~nm}$ LED excitation source was selected to investigate the transient PL decay. 
Theoretical Calculations Method: The ground state geometries of gas state were fully optimized by B3LYP method including Grimme's dispersion correction with 6$31 \mathrm{G}(\mathrm{d}, \mathrm{p})$ basis set using Gaussian 09 software package. ${ }^{[1-5]}$ The HOMO and LUMO were visualized with Gaussview 5.0, and the molecular vibration vector diagrams were drawing in VMD 1.9.4. ${ }^{[6]}$ The excited state properties were calculated by TDDFT with the same theory level as DFT.

The reorganization energy consists of contributions from the external and inner reorganization energy. ${ }^{[7-8]}$ The external reorganization energy that is due to the polarization of the medium can be neglected. ${ }^{[9-10]}$ And the inner reorganization in radiative process is caused by the change of the state geometries from $\mathrm{S} 0$ to $\mathrm{S} 1$, and the value can be estimated as the following. ${ }^{[11]}$

$$
\lambda=\lambda_{\mathrm{S} 0}+\lambda_{\mathrm{S} 1}=\left[E^{\mathrm{S} 0}\left(\mathrm{~S}_{1}\right)-E^{\mathrm{S} 0}\left(\mathrm{~S}_{0}\right)\right]+\left[E^{\mathrm{S} 1}\left(\mathrm{~S}_{0}\right)-E^{\mathrm{S} 1}\left(\mathrm{~S}_{1}\right)\right]
$$

Here, $E^{\mathrm{S} 0}\left(\mathrm{~S}^{1}\right)$ is the energy of the $\mathrm{S}_{0}$ state with the optimized $\mathrm{S}_{1}$ geometry, $E^{\mathrm{S} 0}\left(\mathrm{~S}_{0}\right)$ is the energy of the $\mathrm{S}_{0}$ states with the optimized $\mathrm{S}_{0}$ geometry, $E^{\mathrm{S} 1}\left(\mathrm{~S}_{0}\right)$ is the energy of the $\mathrm{S}_{1}$ states with the optimized $\mathrm{S}_{0}$ geometry, and $E^{\mathrm{S} 1}\left(\mathrm{~S}_{1}\right)$ is the energy of the $\mathrm{S}_{1}$ state with the optimized $\mathrm{S}_{1}$ geometry. The single point energy was calculated at B3LYP level with 6-31G $(\mathrm{d}, \mathrm{p})$ basis set. $^{[12]}$ The decomposition of the reorganization energy was realized by using dushin program. ${ }^{[13]}$

Synthesis of Material: All reagents were purchased from Energy Chemical Co. and $J \& K$ scientific Ltd. Co. and immediately used without further purification. The Schlenk technology was strictly performed under nitrogen conditions in all reactions and the concrete synthesis procedures were showed below in detail. The final product 
was first purified by column chromatography, then temperature-gradient sublimation was utilized to further purify the target compound under high vacuum to obtain highly pure samples.

Synthesis of DtCzB: The synthetic process was referred to the reported literature. ${ }^{[14]}$ Synthesis of DtCzB-Bpin: 4,4 -di-tert-butyl-2,2 -bipyridine (dtbpy) (34.9 mg, 0.13 mmol) and di-mu-methoxobis(1,5-cyclooctadiene)diiridium(I) $\left(\left[\operatorname{Ir}(\mathrm{COD})\left(\mathrm{OCH}_{3}\right)\right]_{2}\right)$ (43.1 mg, $0.065 \mathrm{mmol})$ were added to the suspension of DtCzB (4.20 g, $6.5 \mathrm{mmol})$ and bis(pinacolato)diboron $\left(\mathrm{B}_{2} \mathrm{Pin}\right)(1.68 \mathrm{~g}, 6.6 \mathrm{mmol})$ in extra dry tetrahydrofuran (THF) $(60 \mathrm{~mL})$ at room temperature. Then the mixture was bubbled with nitrogen for further 5 minutes and heated to reflux and stirred for 24 hours. After cooling to room temperature, the reaction mixture was directly concentrated under reduced pressure and purified by column chromatography with using a mixture eluent of dichloromethane/petroleum ether (1:2) to afford a yellow solid (4.50 g). Yield: $90 \% .{ }^{1} \mathrm{H}$

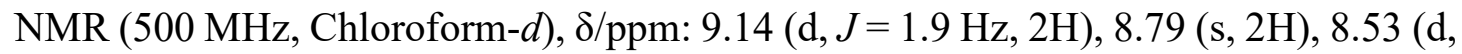
$J=8.8 \mathrm{~Hz}, 2 \mathrm{H}), 8.48(\mathrm{~d}, J=1.8 \mathrm{~Hz}, 2 \mathrm{H}), 8.27(\mathrm{~d}, J=2.0 \mathrm{~Hz}, 2 \mathrm{H}), 7.74(\mathrm{dd}, J=8.8$, $2.1 \mathrm{~Hz}, 2 \mathrm{H}), 1.67(\mathrm{~s}, 18 \mathrm{H}), 1.54(\mathrm{~s}, 18 \mathrm{H}), 1.49(\mathrm{~s}, 12 \mathrm{H}) .{ }^{13} \mathrm{C}\left\{{ }^{1} \mathrm{H}\right\}$ NMR (151 MHz, Chloroform-d) $\delta$ /ppm: 145.17, 144.55, 143.68, 141.64, 138.48, 129.77, 126.93, 124.59, $123.75,121.65,120.75,117.10,114.44,113.77,84.34,35.18,34.82,32.21,31.87$, 25.09. ESI-MS (M): m/z: 765.93 [M]+ (calcd: 766.48). Anal. Calcd for $\mathrm{C}_{52} \mathrm{H}_{60} \mathrm{~B}_{2} \mathrm{~N}_{2} \mathrm{O}_{2}$ : C, 81.46; H, 7.89; N, 3.65. Found: C, 81.48; H, 7.93; N, 3.68.

Synthesis of DtCzB-DPTRZ: 2-chloro-4,6-diphenyl-1,3,5-triazine (160.6 mg, 0.6 mmol), DtCzB-Bpin (383.3 mg, $0.5 \mathrm{mmol})$, potassium carbonate $\left(\mathrm{K}_{2} \mathrm{CO}_{3}\right)(138 \mathrm{mg}, 1$ 
mmol) were added with water $(2 \mathrm{~mL})$ and THF $(16 \mathrm{~mL})$. Then the mixture was bubbled with nitrogen for further 5 minutes, and tetrakis(triphenylphosphine)palladium(0) $\left(\mathrm{Pd}\left(\mathrm{PPh}_{3}\right)_{4}\right)(28.9 \mathrm{mg}, 0.025 \mathrm{mmol})$ was added under a high flow of nitrogen. Then the mixture was heated to reflux and stirred for 12 hours. After cooling to room temperature, the reaction mixture was extracted with dichloromethane and water, and the combined organic layer was condensed in vacuum, and then the crude product was further purified by column chromatography with using a mixture eluent of dichloromethane/petroleum ether (2:1) to afford a yellow solid (239.8 mg). Yield: 55\%. ${ }^{1} \mathrm{H}$ NMR (500 MHz, Chloroform- $d$ ), $\delta$ /ppm: 9.57 (s, 2H), 8.94 (s, 2H), 8.79 (d, $J=7.4 \mathrm{~Hz}, 4 \mathrm{H}), 8.56$ (d, $J=$ $8.7 \mathrm{~Hz}, 2 \mathrm{H}), 8.34(\mathrm{~d}, J=1.8 \mathrm{~Hz}, 2 \mathrm{H}), 8.14(\mathrm{~d}, J=2.0 \mathrm{~Hz}, 2 \mathrm{H}), 7.67(\mathrm{t}, J=7.1 \mathrm{~Hz}, 2 \mathrm{H})$, $7.61(\mathrm{dd}, J=8.4,6.2 \mathrm{~Hz}, 6 \mathrm{H}), 1.67(\mathrm{~s}, 18 \mathrm{H}), 1.56(\mathrm{~s}, 18 \mathrm{H}) .{ }^{13} \mathrm{C}\left\{{ }^{1} \mathrm{H}\right\} \mathrm{NMR}(151 \mathrm{MHz}$, Chloroform- $d$ ) $\delta / \mathrm{ppm}$ : The signal of ${ }^{13} \mathrm{C}$ was not detected due to the very poor solubility of the target compound. ESI-MS (M): m/z: 870.73 [M]+ (calcd: 871.48). Anal. Calcd for $\mathrm{C}_{61} \mathrm{H}_{58} \mathrm{BN}_{5}$ : C, 84.02; $\mathrm{H}, 6.70 ; \mathrm{N}, 8.03$. Found: $\mathrm{C}, 84.08 ; \mathrm{H}, 6.71 ; \mathrm{N}, 8.09$.

Synthesis of DtCzB-TPTRZ, DtCzB-PPm and DtCzB-CNPm: They were synthesized in the same way of preparing DtCzB-DPTRZ, just replaced 2-chloro-4,6diphenyl-1,3,5-triazine with equivalent stoichiometric 2-(4-bromophenyl)-4,6diphenyl-1,3,5-triazine, 5-bromo-2-phenylpyrimidine and 5-bromo-2-cyanopyrimidine, respectively.

DtCzB-TPTRZ: yellow solid (293.9 mg). Yield: 62\%. ${ }^{1} \mathrm{H}$ NMR (500 MHz, Chloroform- $d$ ), $\delta /$ ppm: $9.10(\mathrm{~d}, J=19.0 \mathrm{~Hz}, 2 \mathrm{H}), 9.04-8.95(\mathrm{~m}, 2 \mathrm{H}), 8.86-8.71(\mathrm{~m}$, 4H), $8.64-8.54(\mathrm{~m}, 2 \mathrm{H}), 8.51-8.41(\mathrm{~m}, 4 \mathrm{H}), 8.26(\mathrm{~d}, J=9.6 \mathrm{~Hz}, 2 \mathrm{H}), 8.18-8.07(\mathrm{~m}$, 
2H), $7.71(\mathrm{dt}, J=8.9,1.9 \mathrm{~Hz}, 2 \mathrm{H}), 7.59(\mathrm{dq}, J=15.8,8.2,7.7 \mathrm{~Hz}, 6 \mathrm{H}), 1.68(\mathrm{~s}, 18 \mathrm{H})$, 1.55 (s, 18H). ${ }^{13} \mathrm{C}\left\{{ }^{1} \mathrm{H}\right\}$ NMR (151 MHz, Chloroform- $d$ ) $\delta /$ ppm: 171.65, 171.22, 145.60, $145.44,145.02,144.74,141.76,138.31,136.24,136.12,132.53,129.83,129.01$, $128.63,128.00,127.21,124.52,123.67,122.53,121.72,120.72,117.37,114.17,107.01$, 35.19, 34.83, 32.21, 31.85. ESI-MS (M): m/z: 946.57 [M]+ (calcd: 947.51). Anal. Calcd for $\mathrm{C}_{67} \mathrm{H}_{62} \mathrm{BN}_{5}: \mathrm{C}, 84.88 ; \mathrm{H}, 6.59 ; \mathrm{N}, 7.39$. Found: $\mathrm{C}, 84.89 ; \mathrm{H}, 6.66 ; \mathrm{N}, 7.38$.

DtCzB-PPm: yellow solid (238.5 mg). Yield: 60\%. ${ }^{1} \mathrm{H}$ NMR (500 MHz, Chloroformd), $\delta / \mathrm{ppm}: 9.27-9.15(\mathrm{~m}, 2 \mathrm{H}), 8.96(\mathrm{~s}, 2 \mathrm{H}), 8.65(\mathrm{dd}, J=6.6,3.7 \mathrm{~Hz}, 2 \mathrm{H}), 8.39(\mathrm{dt}, J$ $=5.3,2.1 \mathrm{~Hz}, 2 \mathrm{H}), 8.31-8.15(\mathrm{~m}, 6 \mathrm{H}), 7.62(\mathrm{dt}, J=6.7,2.6 \mathrm{~Hz}, 5 \mathrm{H}), 1.65(\mathrm{~s}, 18 \mathrm{H})$, $1.53(\mathrm{~s}, 18 \mathrm{H}) .{ }^{13} \mathrm{C}\left\{{ }^{1} \mathrm{H}\right\}$ NMR (151 MHz, Chloroform- $\left.d\right) \delta / \mathrm{ppm}: 155.53,145.53,144.81$, $141.55,138.22,138.04,136.87,131.86,131.21,129.64,128.81,128.40,127.16$, $124.55,123.66,122.71,121.54,120.94,117.42,114.12,105.58,35.17,34.80,32.15$, 31.80. ESI-MS (M): m/z: 793.80 [M]+ (calcd: 794.45). Anal. Calcd for $\mathrm{C}_{56} \mathrm{H}_{55} \mathrm{BN}_{4}: \mathrm{C}$, 84.62; H, 6.97; N, 7.05. Found: C, 84.69; H, 6.99; N, 7.10.

DtCzB-CNPm: orange solid (238.0 mg). Yield: 64\%. ${ }^{1} \mathrm{H}$ NMR (500 MHz, Chloroform- $d$ ), $\delta /$ ppm: $8.16(\mathrm{~s}, 4 \mathrm{H}), 7.96(\mathrm{~d}, J=9.0 \mathrm{~Hz}, 2 \mathrm{H}), 7.82-7.77(\mathrm{~m}, 2 \mathrm{H}), 7.59$ (s, 2H), $7.48(\mathrm{~d}, J=8.4 \mathrm{~Hz}, 2 \mathrm{H}), 7.21(\mathrm{~s}, 2 \mathrm{H}), 1.54(\mathrm{~s}, 18 \mathrm{H}), 1.49(\mathrm{~s}, 18 \mathrm{H}) .{ }^{13} \mathrm{C}\left\{{ }^{1} \mathrm{H}\right\}$ NMR (151 MHz, Chloroform-d) $\delta /$ ppm: 155.86, 146.04, 145.11, 144.78, 143.92, $141.38,137.81,135.88,129.58,127.17,124.69,123.64,121.20,117.57,116.99,115.84$ 113.97, 105.60, 32.10, 31.77. ESI-MS (M): m/z: 742.84 [M]+ (calcd: 743.42). Anal. Calcd for $\mathrm{C}_{51} \mathrm{H}_{50} \mathrm{BN}_{5}:$ C, 82.35; H, 6.78; N, 9.42. Found: C, 82.40; H, 6.82; N, 9.48. 
Device Fabrication and Measurements: Before device fabrication, the indium tin oxide (ITO) glass substrates with a sheet resistance of $15 \Omega$ per square were treated with plasma for $5 \mathrm{~min}$, after cleaning with optical detergents, deionized water, acetone and isopropanol successively. Then they were transferred to a vacuum chamber in a nitrogen-filled glove box. Under high vacuum $\left(<9 \times 10^{-5} \mathrm{~Pa}\right)$, the organic materials were deposited onto the ITO glass substrates at a rate of $1 \AA \mathrm{s}^{-1}$. After finishing the deposition of organic layers, ITO glass substrates were patterned by a shadow mask with an array of $2.0 \mathrm{~mm} \times 2.5 \mathrm{~mm}$ openings. Then $\mathrm{LiF}$ and $\mathrm{Al}$ were successively deposited at a rate of $0.1 \AA \mathrm{s}^{-1}$ and $5 \AA \mathrm{s}^{-1}$, respectively. The EL spectra, CIE coordinates and luminance intensities of the OLEDs were recorded by Photo Research PR655, simultaneously, the current density $(J)$ and driving voltage $(V)$ were recorded by Keithley 2400. By assuming a Lambertian distribution, the EQE was estimated based on the brightness, electroluminescence spectrum, and current density.

Calculation Formulas for the Photophysical Parameters: The calculation formulas for the rate constants of fluorescent $\left(k_{\mathrm{F}}\right)$, internal conversion $\left(k_{\mathrm{IC}}\right)$, intersystem crossing $\left(k_{\mathrm{ISC}}\right)$, TADF $\left(k_{\mathrm{TADF}}\right)$ and reverse intersystem crossing $\left(k_{\mathrm{RISC}}\right)$ are expressed as following list: ${ }^{[15-18]}$

$$
\begin{aligned}
& k_{\mathrm{F}}=\Phi_{\mathrm{F}} / \tau_{\mathrm{F}} \\
& \Phi_{\mathrm{PL}}=k_{\mathrm{F}} /\left(k_{\mathrm{F}}+k_{\mathrm{IC}}\right) \\
& \Phi_{\mathrm{F}}=k_{\mathrm{F}} /\left(k_{\mathrm{F}}+k_{\mathrm{IC}}+k_{\mathrm{ISC}}\right) \\
& \Phi_{\mathrm{ISC}}=k_{\mathrm{ISC}} /\left(k_{\mathrm{F}}+k_{\mathrm{IC}}+k_{\mathrm{ISC}}\right) \\
& k_{\mathrm{TADF}}=\Phi_{\mathrm{TADF}} /\left(\Phi_{\mathrm{ISC}} \tau_{\mathrm{TADF}}\right) \\
& k_{R \mathrm{ISC}}=k_{\mathrm{F}} k_{\mathrm{TADF}} \Phi_{\mathrm{TADF}} /\left(k_{\mathrm{ISC}} \Phi_{\mathrm{F}}\right) \\
& \Phi_{\mathrm{TADF}} / \Phi_{\mathrm{F}}=\left(\Phi_{\mathrm{ISC}} \Phi_{\mathrm{RISC}}\right) /\left(1-\Phi_{\mathrm{ISC}} \Phi_{\mathrm{RISC}}\right)
\end{aligned}
$$

Where $\Phi_{\mathrm{PL}}$ is the total fluorescence quantum yield, $\Phi_{\mathrm{F}}$ is the prompt fluorescent component of $\Phi_{\mathrm{PL}}, \Phi_{\mathrm{TADF}}$ is the delayed fluorescent component of $\Phi_{\mathrm{PL}} . \tau_{\mathrm{F}}$ is the lifetime 
of prompt fluorescent, $\tau_{\mathrm{TADF}}$ is the lifetime of TADF, $k_{\mathrm{F}}$ is the rate constant of fluorescent. $k_{\mathrm{IC}}$ is the rate constant of internal conversion; $k_{\mathrm{TADF}}, k_{\mathrm{ISC}}, k_{\mathrm{RISC}}$ are the rate constants of TADF, intersystem crossing and reverse intersystem crossing, respectively. $\Phi_{\text {ISC }}$ and $\Phi_{\mathrm{RISC}}$ are the quantum efficiencies of ISC and RISC process, respectively.
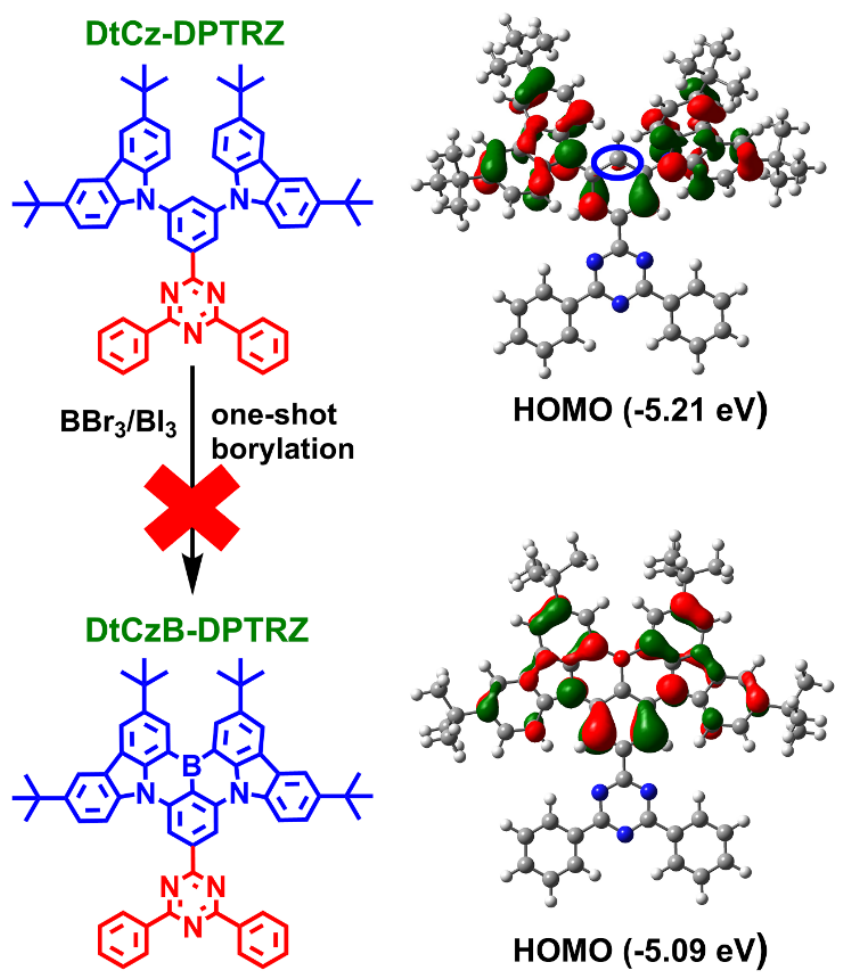

Figure S1. Calculated HOMO distributions of DtCz-DPTRZ and DtCzB-DPTRZ. There is nearly no HOMO distribution (blue circle) on the para-carbon position of the DPTRZ-substituted phenyl-ring, which is attributed to the strong electron withdrawing ability of that, suggesting that it will be very difficult for borylation reaction on the carbon to afford DtCzB-DPTRZ. 

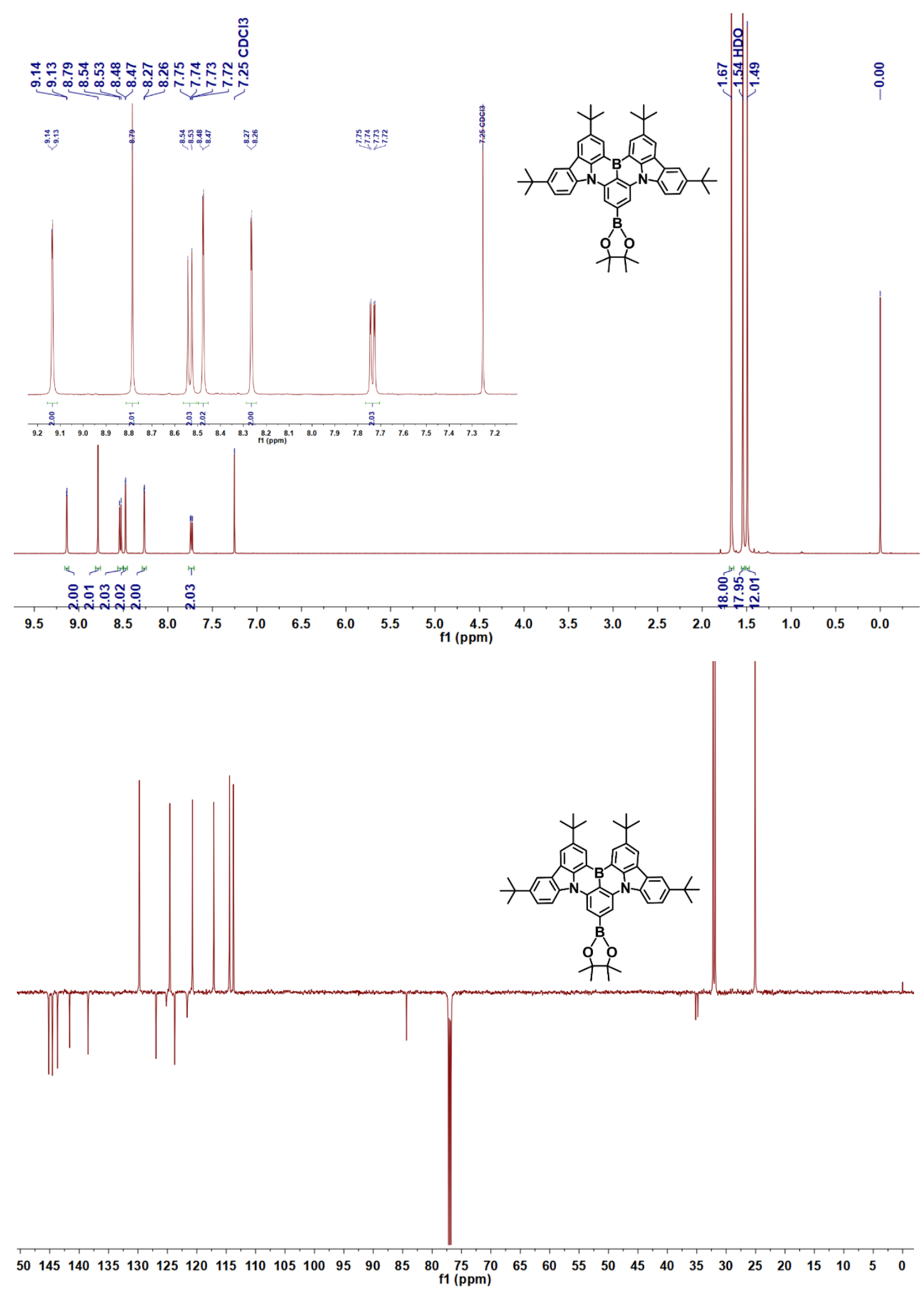

Figure S2. ${ }^{1} \mathrm{H}$ NMR spectrum $\left(500 \mathrm{MHz}, \mathrm{CDCl}_{3}\right)$ and ${ }^{13} \mathrm{C}\left\{{ }^{1} \mathrm{H}\right\}$ NMR spectrum $(151$ $\mathrm{MHz}, \mathrm{CDCl}_{3}$ ) of DtCzB-Bpin. 

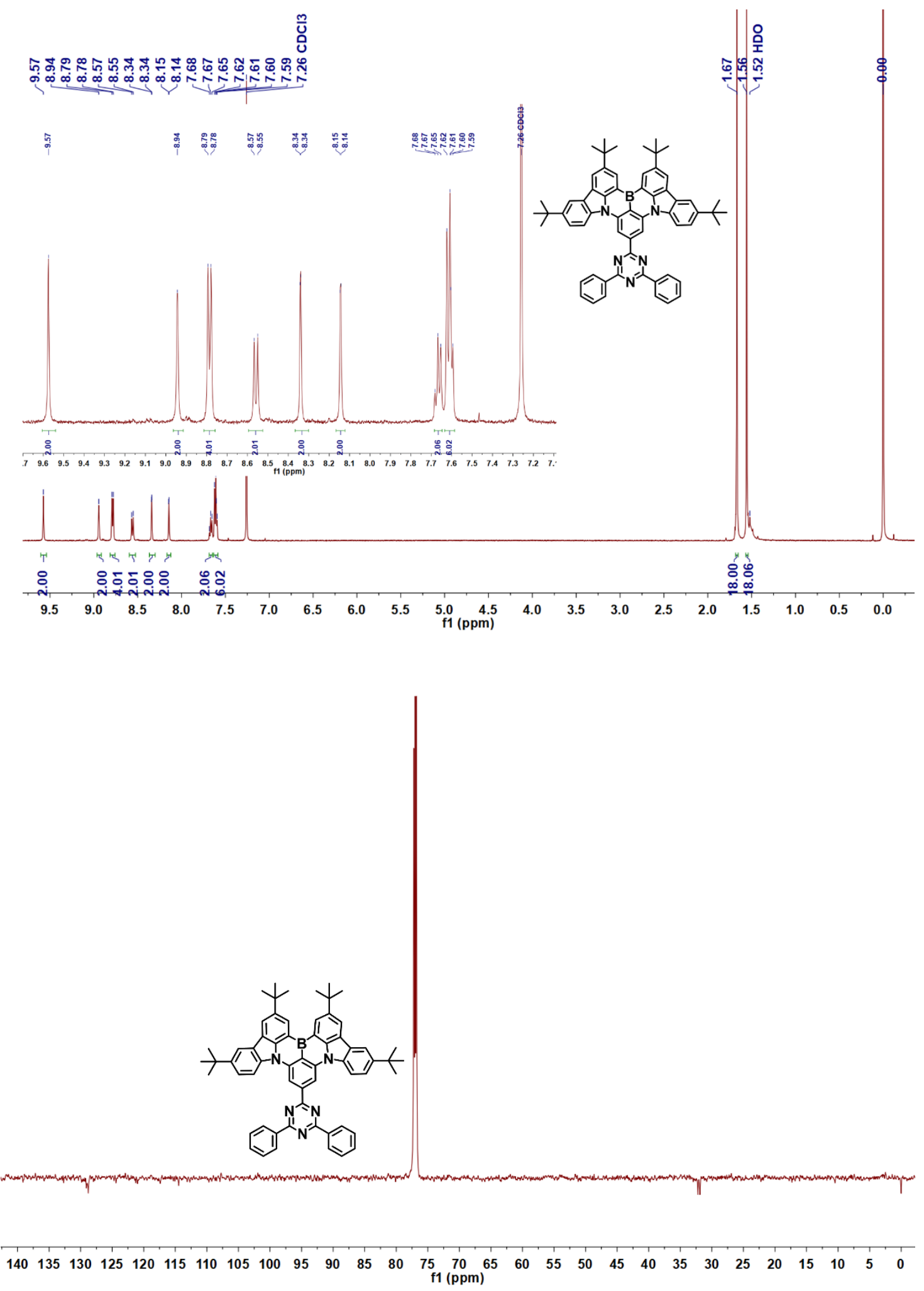

Figure S3. ${ }^{1} \mathrm{H}$ NMR spectrum $\left(500 \mathrm{MHz}, \mathrm{CDCl}_{3}\right)$ and ${ }^{13} \mathrm{C}\left\{{ }^{1} \mathrm{H}\right\}$ NMR spectrum $(151$ $\mathrm{MHz}, \mathrm{CDCl}_{3}$ ) of DtCzB-DPTRZ. 


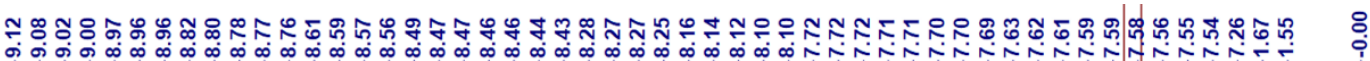

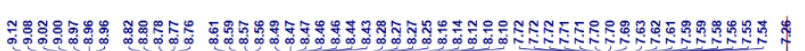
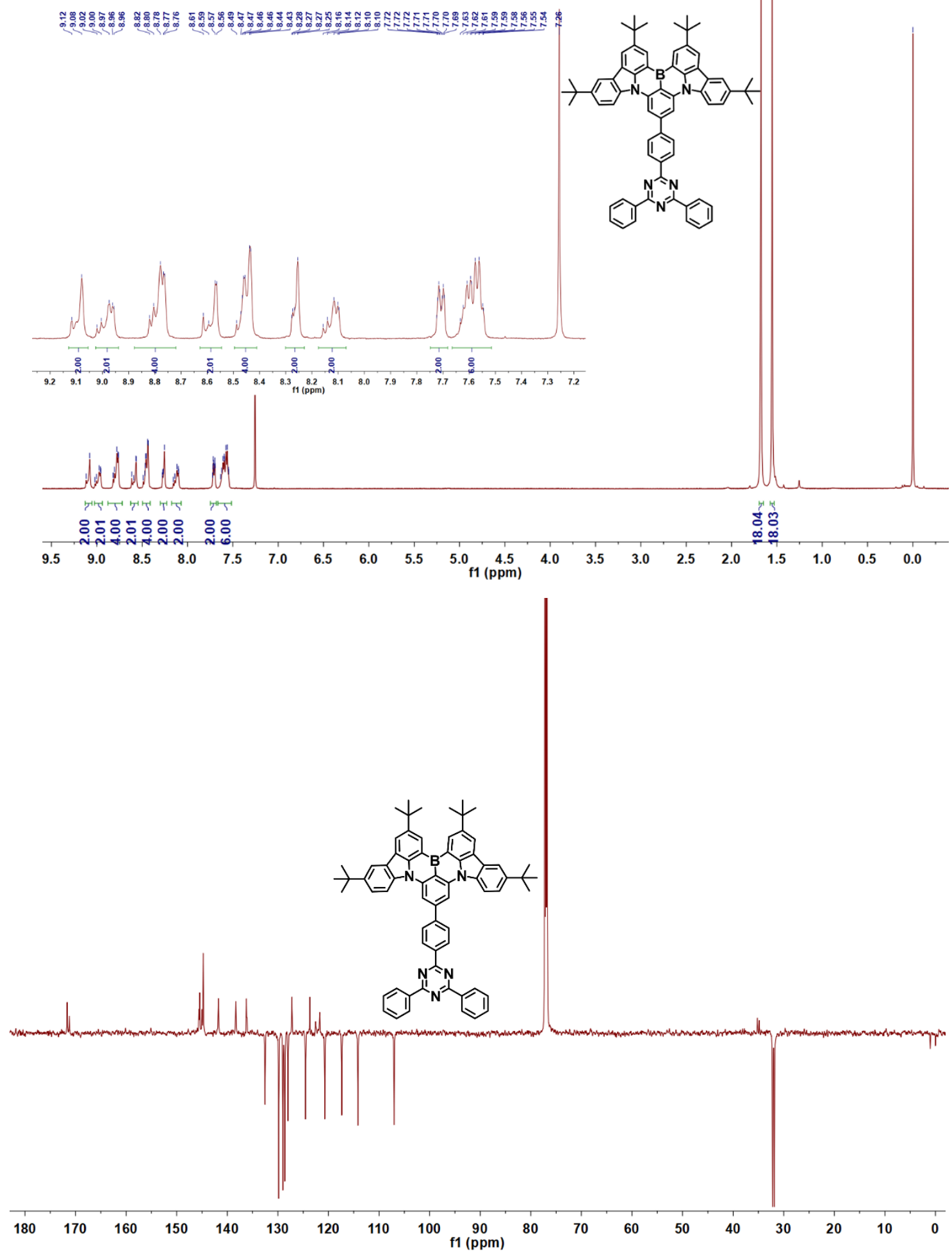

Figure S4. ${ }^{1} \mathrm{H}$ NMR spectrum $\left(500 \mathrm{MHz}, \mathrm{CDCl}_{3}\right)$ and ${ }^{13} \mathrm{C}\left\{{ }^{1} \mathrm{H}\right\}$ NMR spectrum $(151$ $\mathrm{MHz}, \mathrm{CDCl}_{3}$ ) of DtCzB-TPTRZ. 

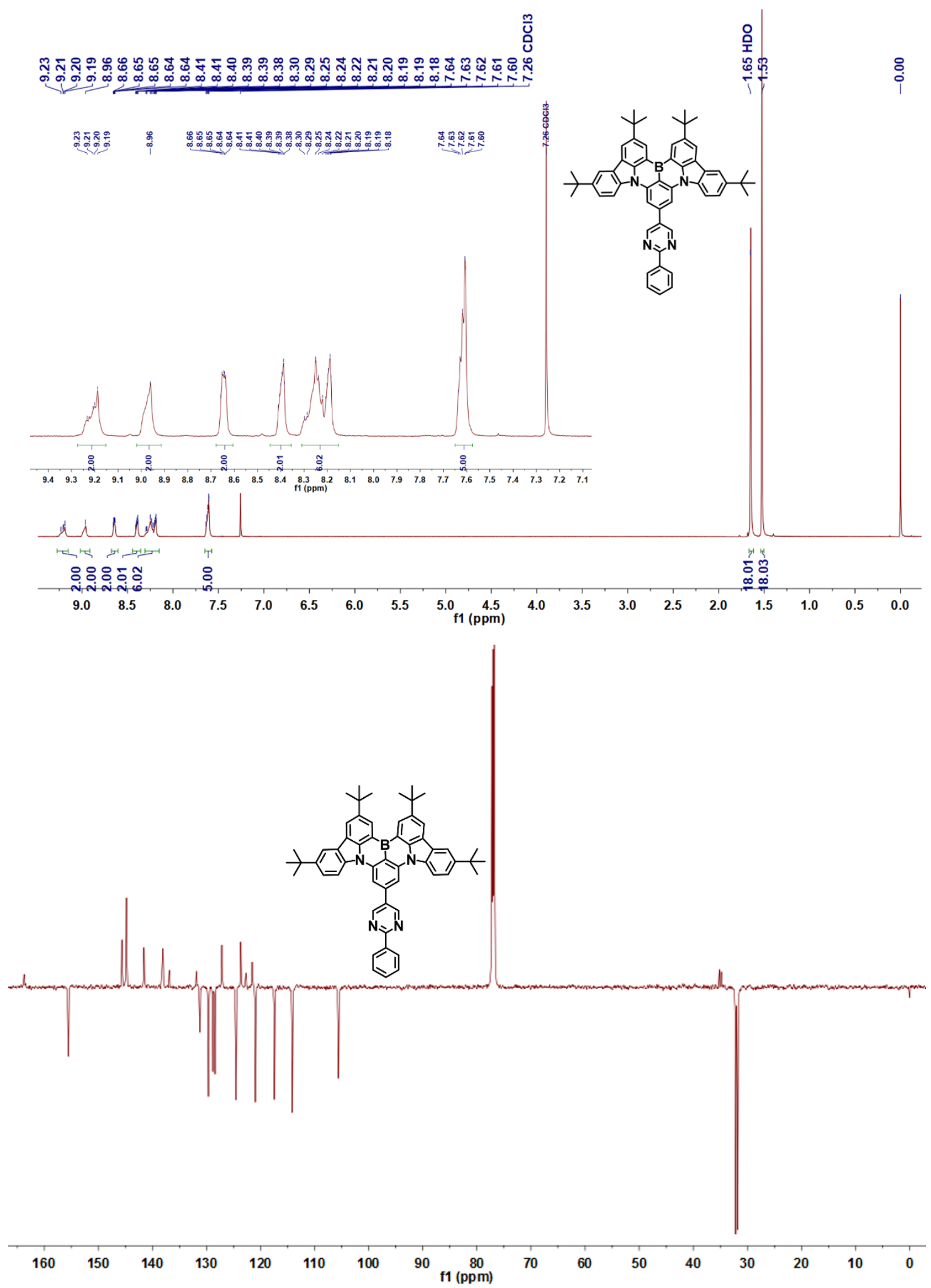

Figure S5. ${ }^{1} \mathrm{H}$ NMR spectrum $\left(500 \mathrm{MHz}, \mathrm{CDCl}_{3}\right)$ and ${ }^{13} \mathrm{C}\left\{{ }^{1} \mathrm{H}\right\}$ NMR spectrum $(151$ $\mathrm{MHz}, \mathrm{CDCl}_{3}$ ) of DtCzB-PPm. 


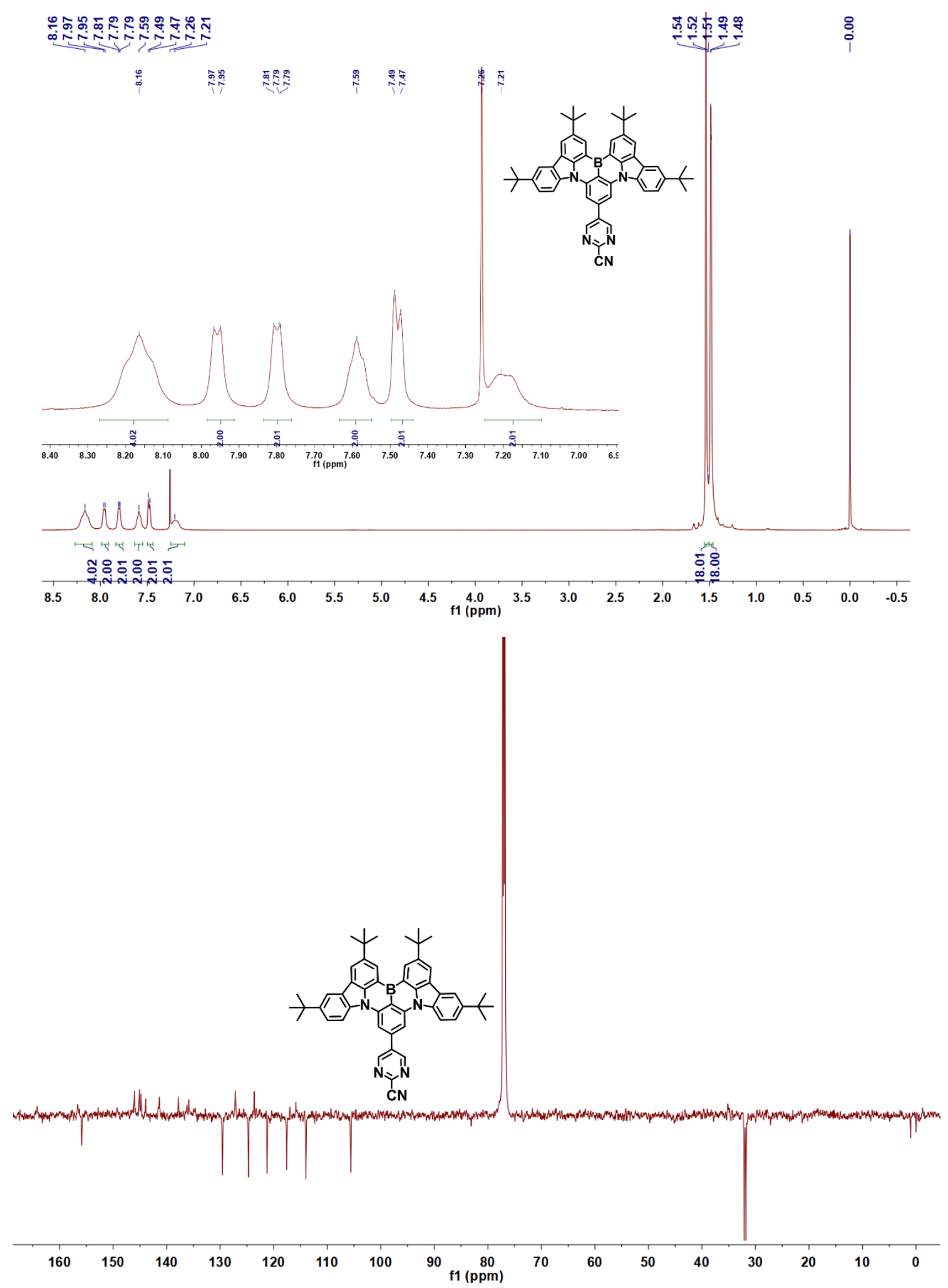

Figure S6. ${ }^{1} \mathrm{H}$ NMR spectrum $\left(500 \mathrm{MHz}, \mathrm{CDCl}_{3}\right)$ and ${ }^{13} \mathrm{C}\left\{{ }^{1} \mathrm{H}\right\}$ NMR spectrum $(151$ $\mathrm{MHz}, \mathrm{CDCl}_{3}$ ) of DtCzB-CNPm. 

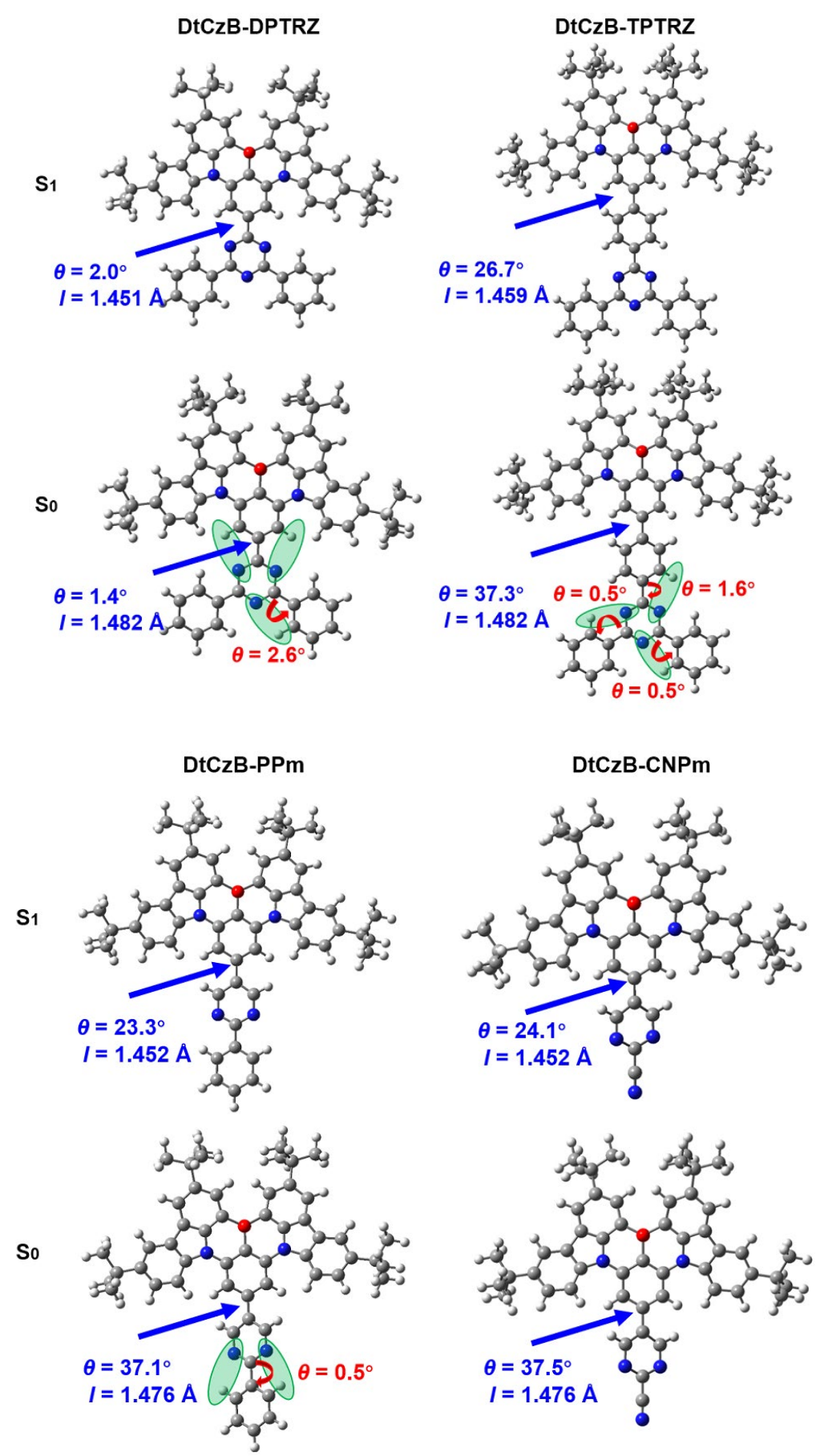

Figure S7. Optimized geometrical configurations of the $S_{0}$ and $S_{1}$ states. Pairs of hydrogen-bonded atoms are indicated by green ovals. Bond length of the linking carbon atoms between the EWG moiety and parent molecule DtCzB. Dihedral angle between two molecular fragments containing all in-plane atoms of the respective moieties flanking the rotatable bond. 


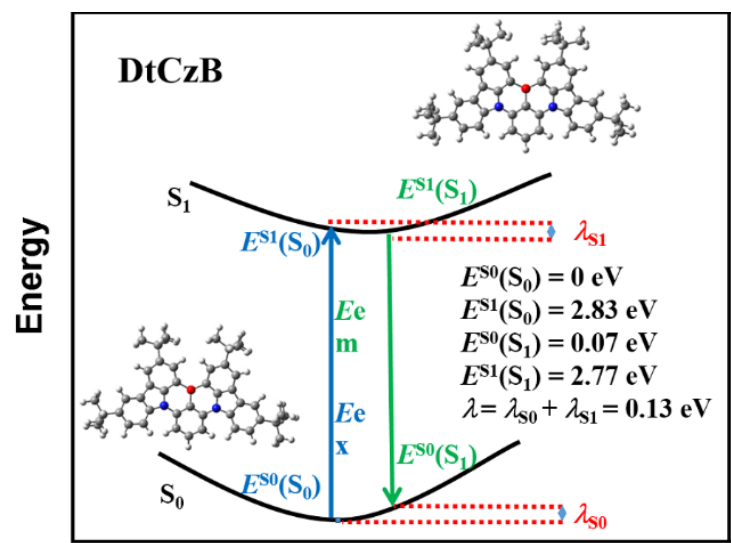

Geometry

Figure S8. Optimized $\mathrm{S}_{0}$ and $\mathrm{S}_{1}$ structures, single point energies and reorganization energies $(\lambda)$.
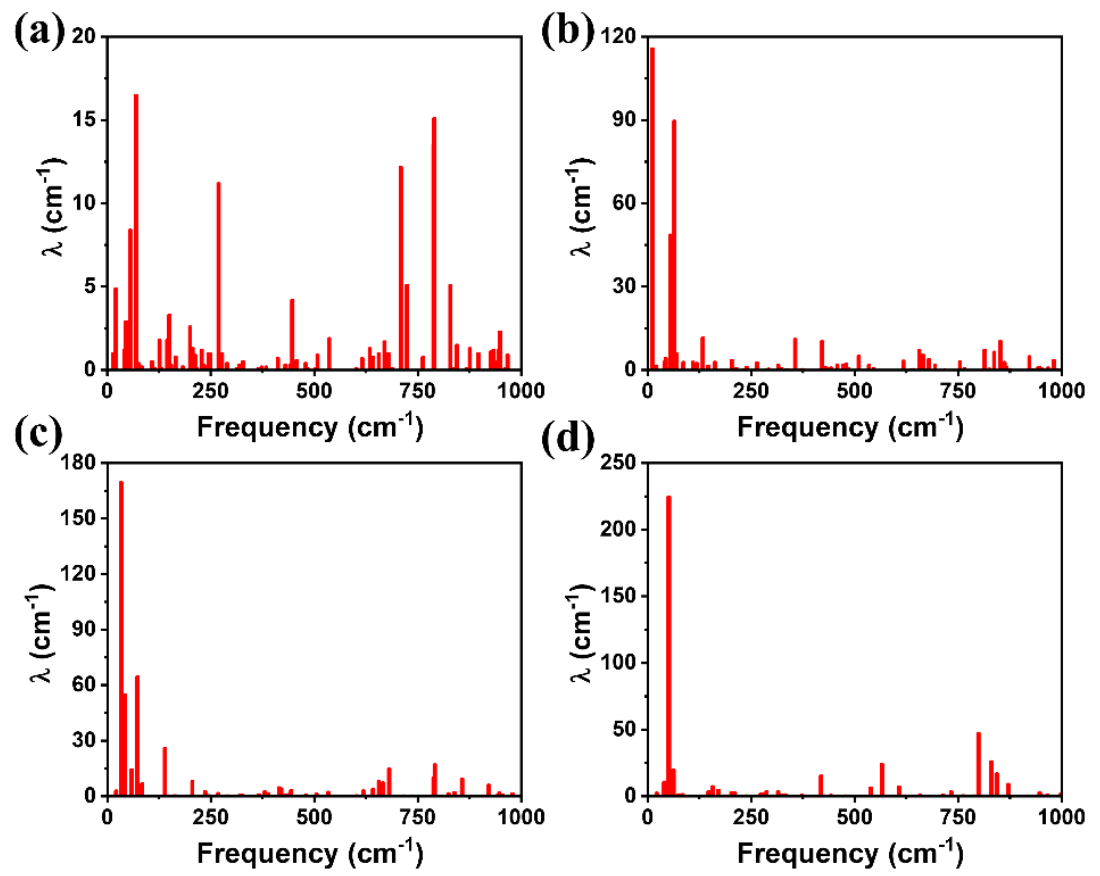

Figure S9. Reorganization energies $(\lambda)$ versus frequency from $\mathrm{S}_{1}$ to $\mathrm{S}_{0}$ of DtCzBDPTRZ (a), DtCzB-TPTRZ (b), DtCzB-PPm (c) and DtCzB-CNPm (d). 


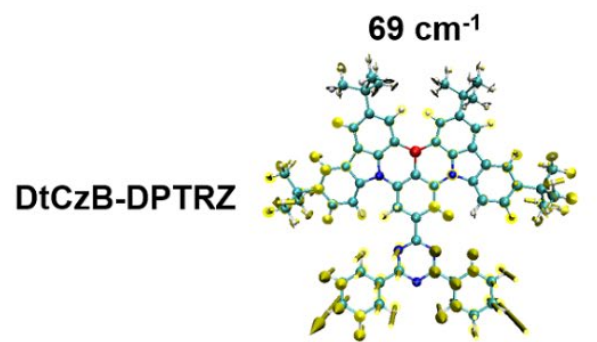

$11 \mathrm{~cm}^{-1}$

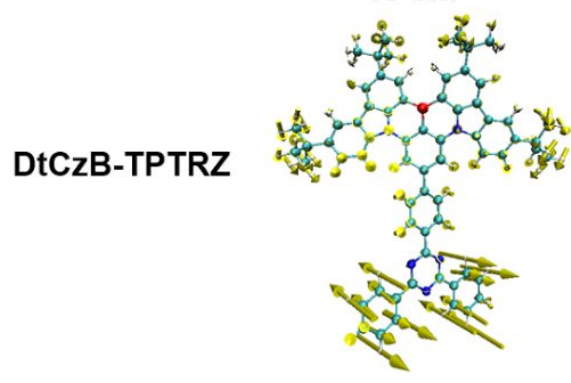

$33 \mathrm{~cm}^{-1}$
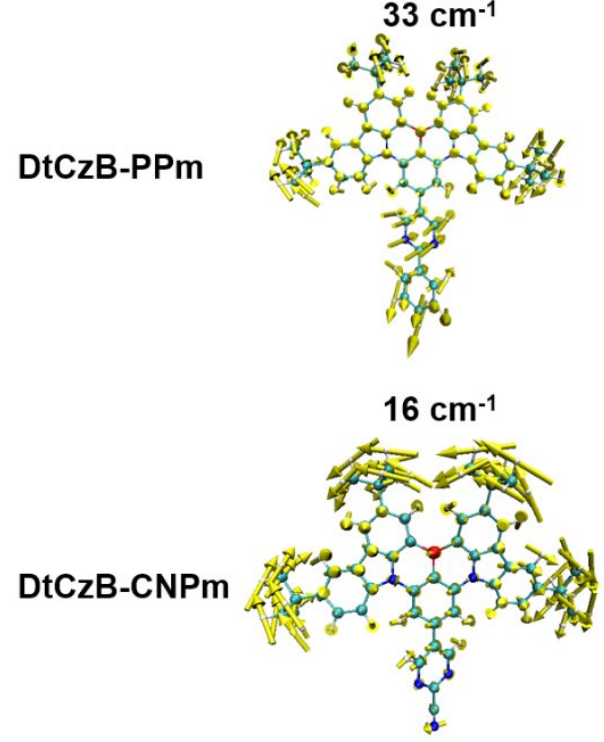
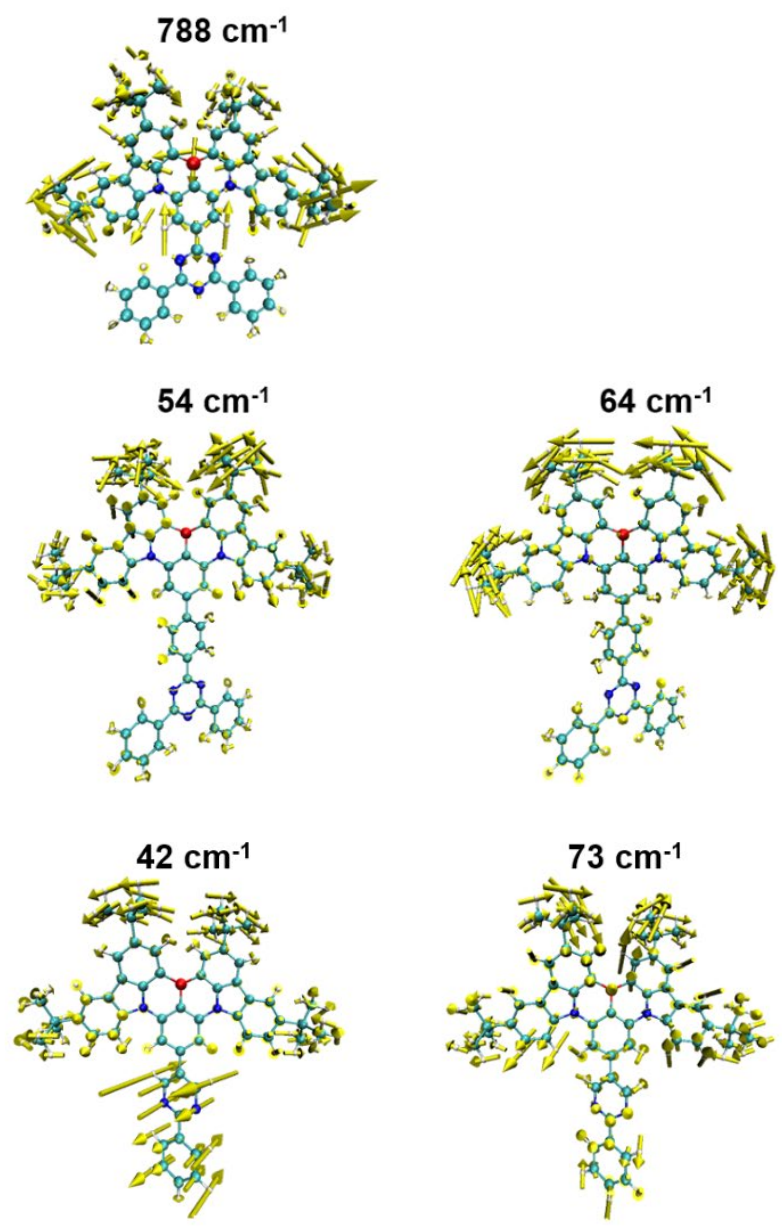

Figure S10. Molecular vibration vector diagrams of the crucial vibrational modes with large contribution to reorganization energies. 
(a)

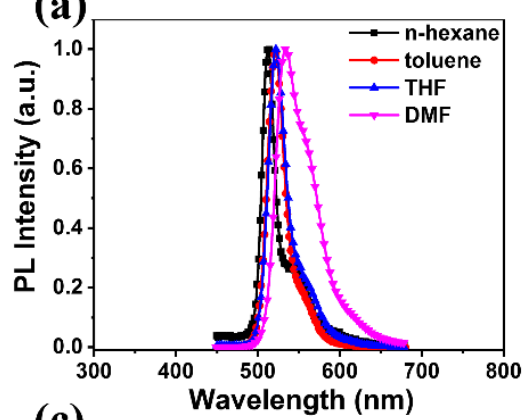

(c)

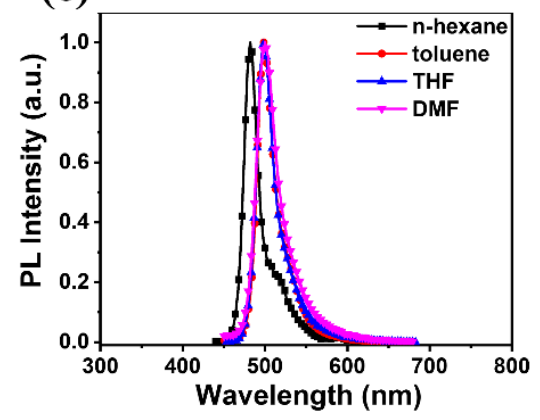

(b)

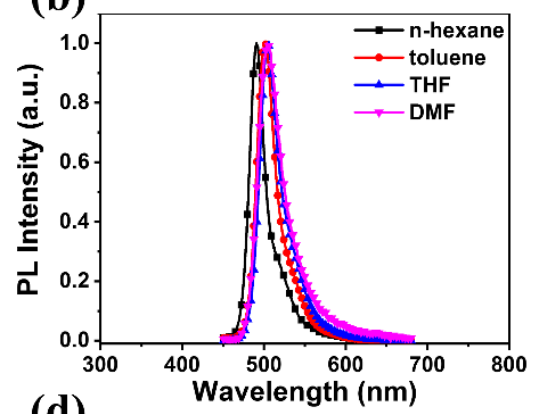

(d)

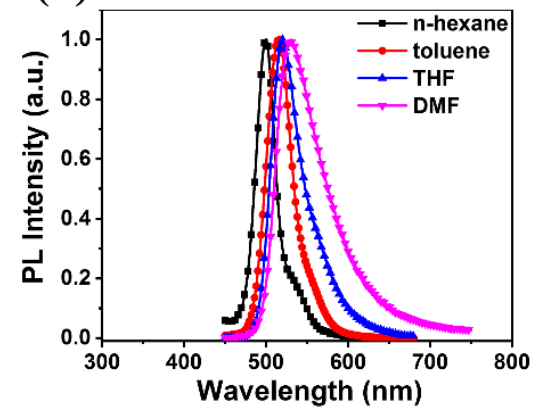

Figure S11. PL spectra in different polar solvents $\left(1 \times 10^{-5} \mathrm{M}, 298 \mathrm{~K}\right)$ of DtCzBDPTRZ (a), DtCzB-TPTRZ (b), DtCzB-PPm (c) and DtCzB-CNPm (d).

(a)

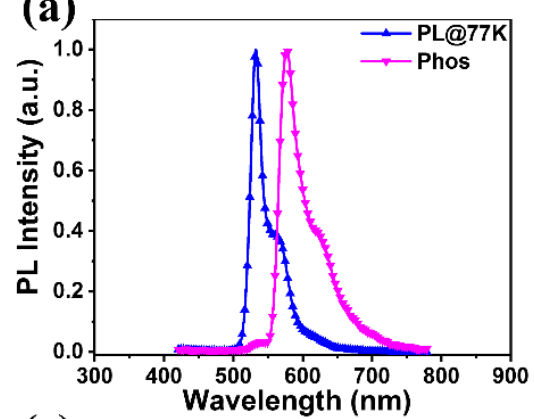

(c)

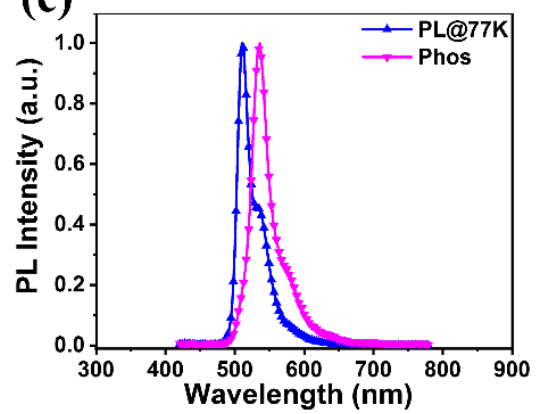

(b)

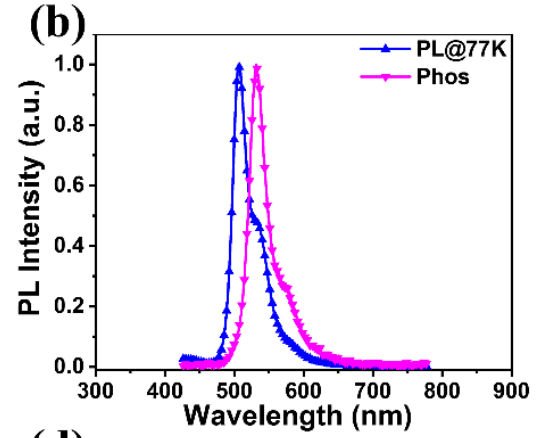

(d)

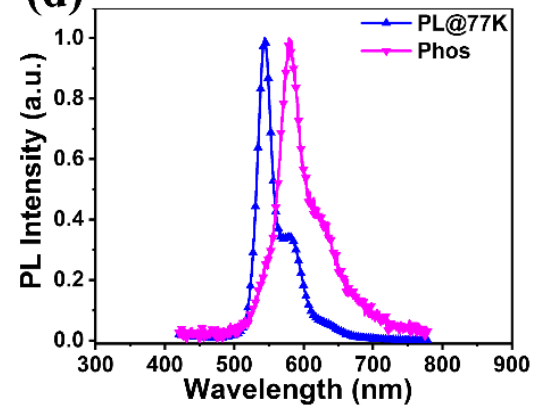

Figure S12. Normalized fluorescence and phosphorescence spectra in toluene solution $\left(1 \times 10^{-5} \mathrm{M}, 77 \mathrm{~K}\right)$ of DtCzB-DPTRZ (a), DtCzB-TPTRZ (b), DtCzB-PPm (c) and $\operatorname{DtCzB}-\mathrm{CNPm}(\mathrm{d})$. 


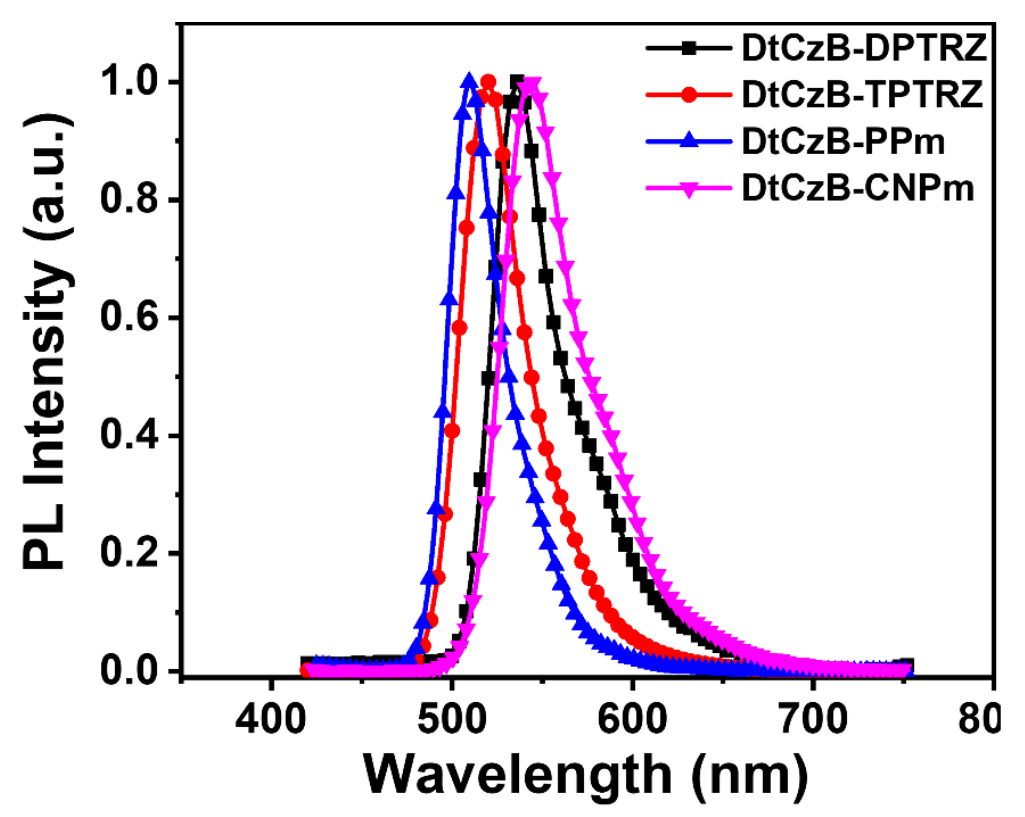

Figure S13. PL spectra of $3 \mathrm{wt} \%$ doping concentration of the investigated compounds in $\mathrm{PhCzBCz}$ deposited films.
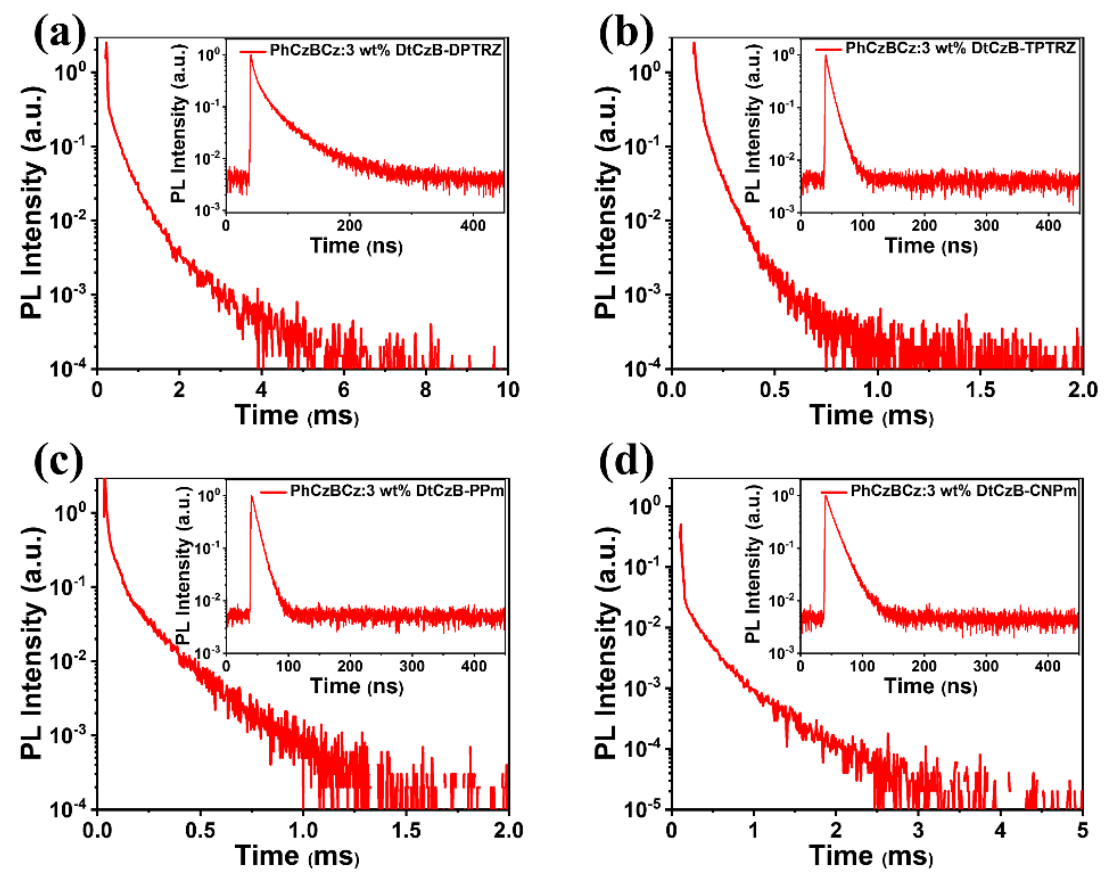

Figure S14. Transient PL decay spectra recorded at $298 \mathrm{~K}$ and under vacuum atmosphere of $3 \mathrm{wt} \%$ doping concentration of DtCzB-DPTRZ (a), DtCzB-TPTRZ (b), DtCzB-PPm (c) and DtCzB-CNPm (d) in PhCzBCz deposited films. 

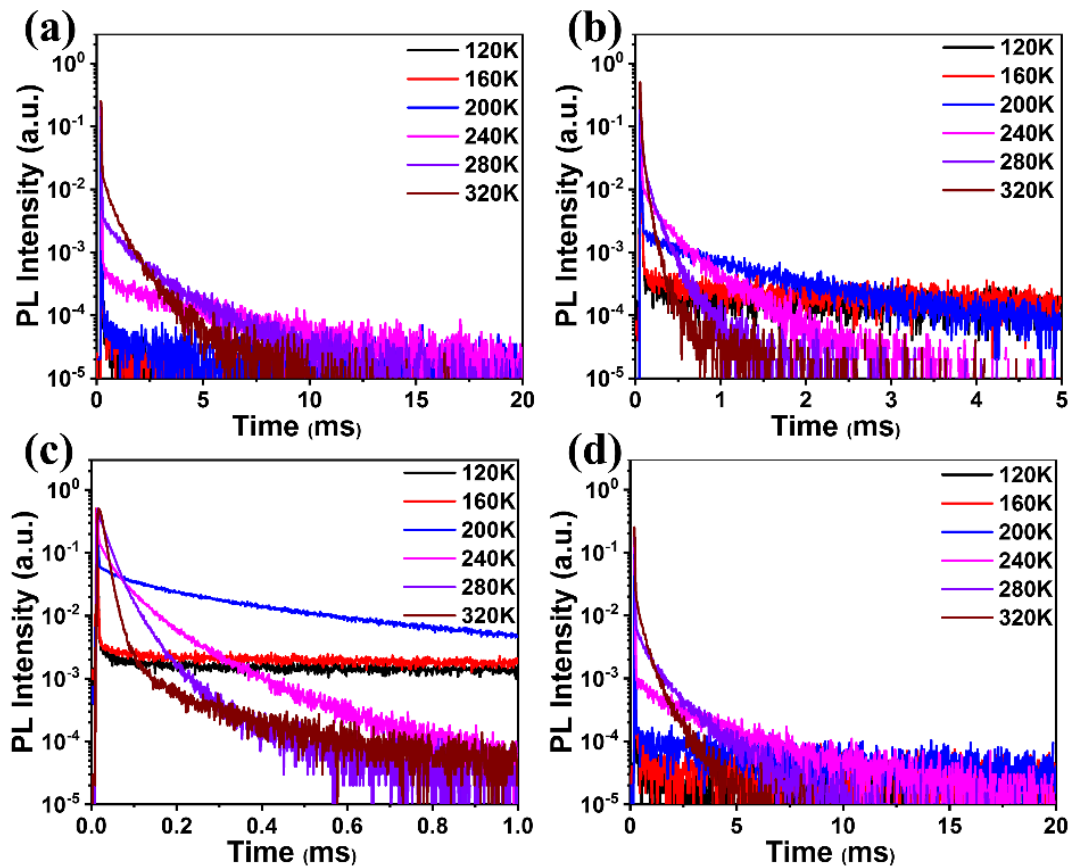

Figure S15. Variable-temperature transient PL decay spectra of $3 \mathrm{wt} \%$ doping concentration of DtCzB-DPTRZ (a), DtCzB-TPTRZ (b), DtCzB-PPm (c) and DtCzBCNPm (d) in $\mathrm{PhCzBCz}$ deposited films.
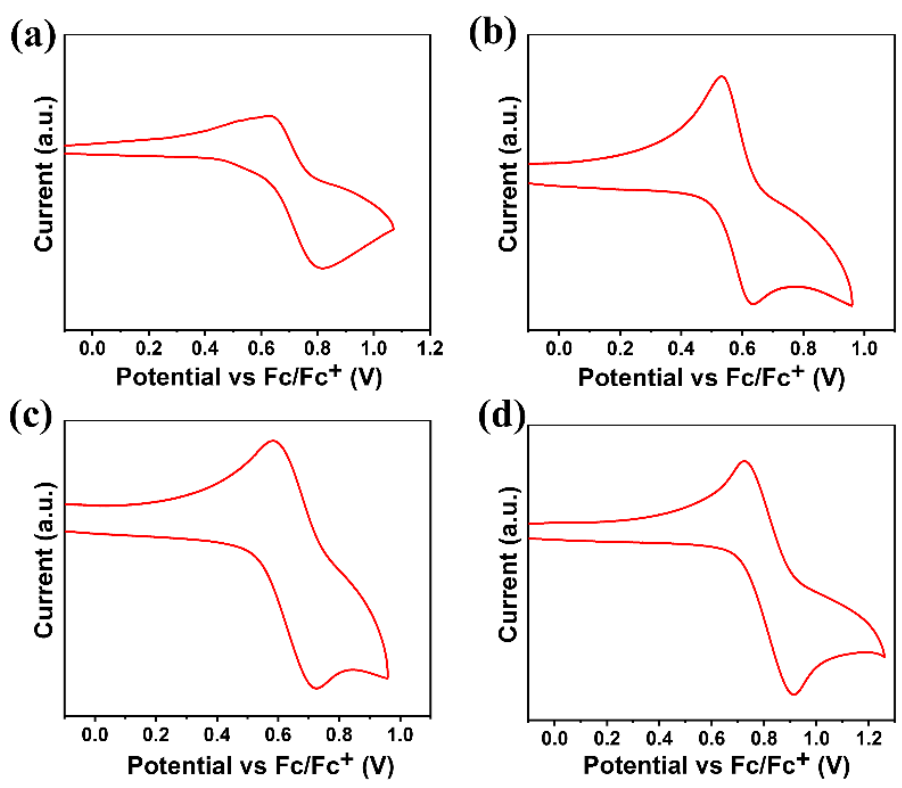

Figure S16. CV curves of DtCzB-DPTRZ (a), DtCzB-TPTRZ (b), DtCzB-PPm (c) and DtCzB-CNPm (d). 
(a)

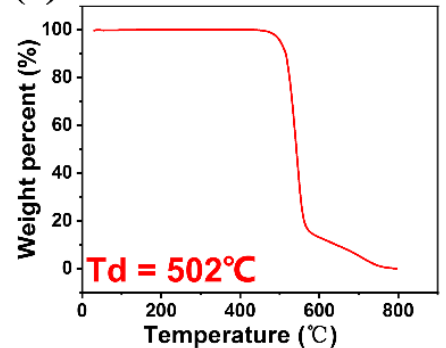

(d)

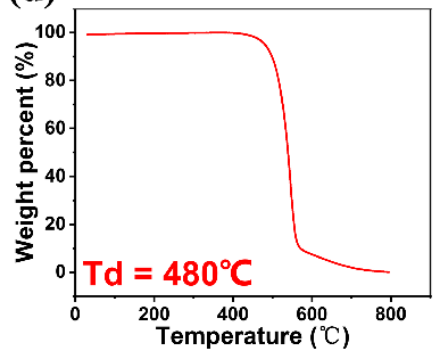

(b)

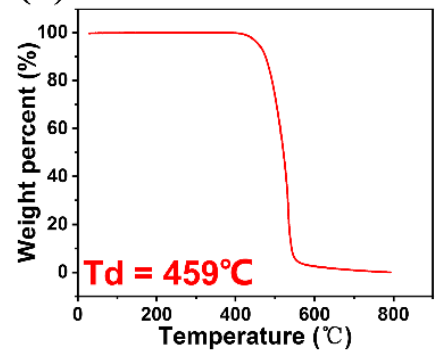

(e)

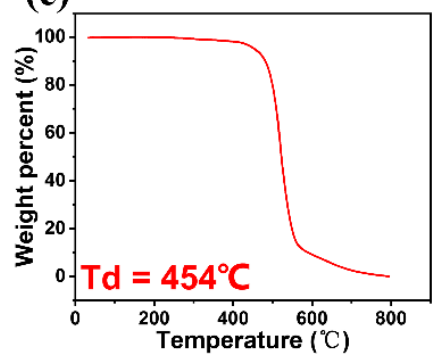

Figure S17. TGA curves of DtCzB-DPTRZ (a), DtCzB-TPTRZ (b), DtCzB-PPm (c) and DtCzB-CNPm (d).

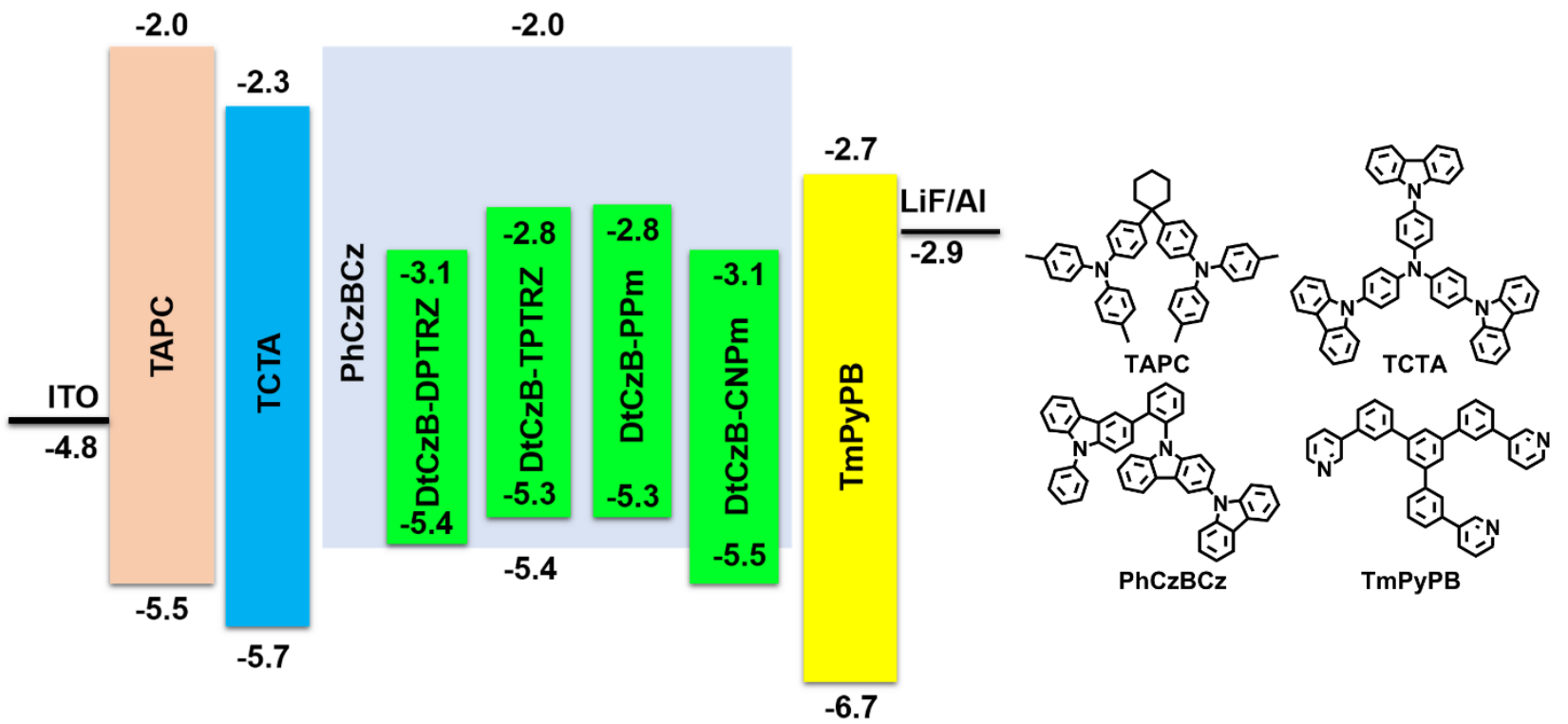

Figure S18. The energy level diagram of OLEDs and the structures of materials used in the devices. 


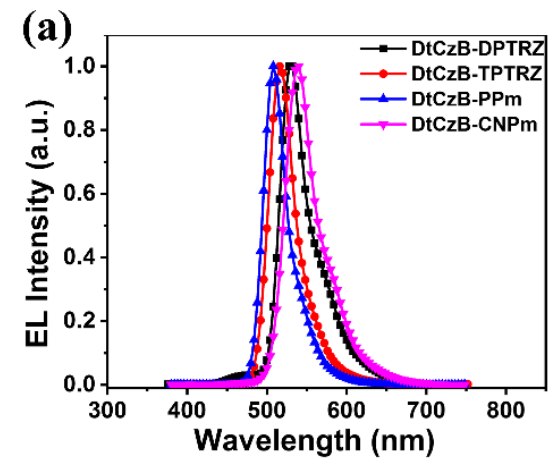

(c)

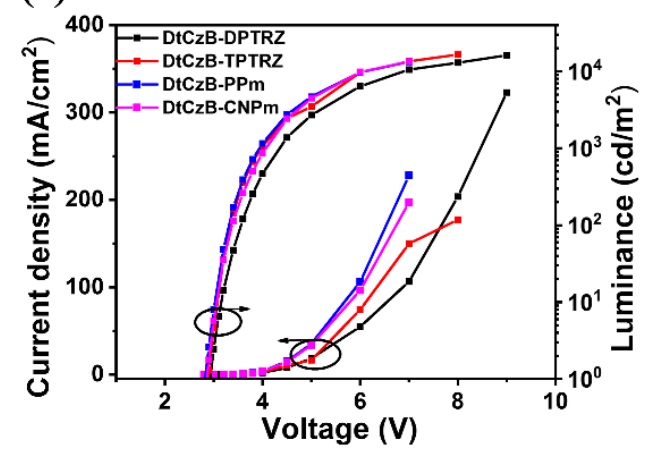

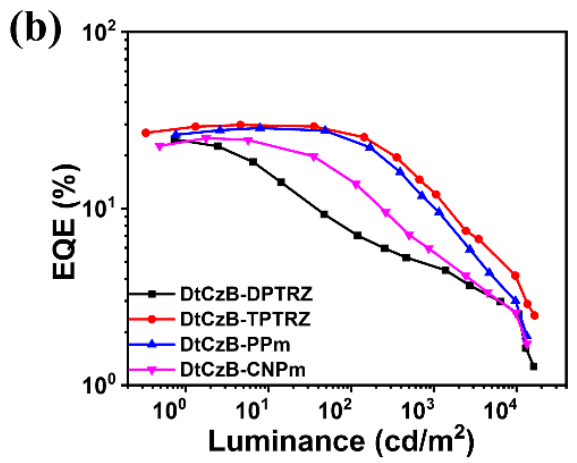

(d)

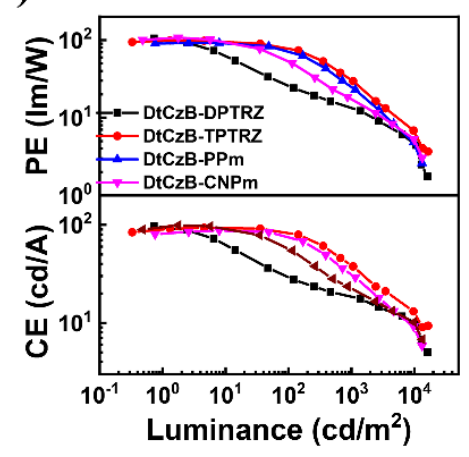

Figure S19. The EL characteristics of the devices with the configuration of ITO/TAPC $(50 \mathrm{~nm}) / \mathrm{TCTA}(5 \mathrm{~nm}) / \mathrm{PhCzBCz}: 3 \mathrm{wt} \%$ the investigated compounds $(30 \mathrm{~nm}) / \mathrm{TmPyPB}$ $(30 \mathrm{~nm}) / \mathrm{LiF}(1 \mathrm{~nm}) / \mathrm{Al}(100 \mathrm{~nm})$. a) EL spectra. b) EQE- $L$ curves. c) $J-V-L$ curves. d) CE- $L$ and PE- $L$ curves.

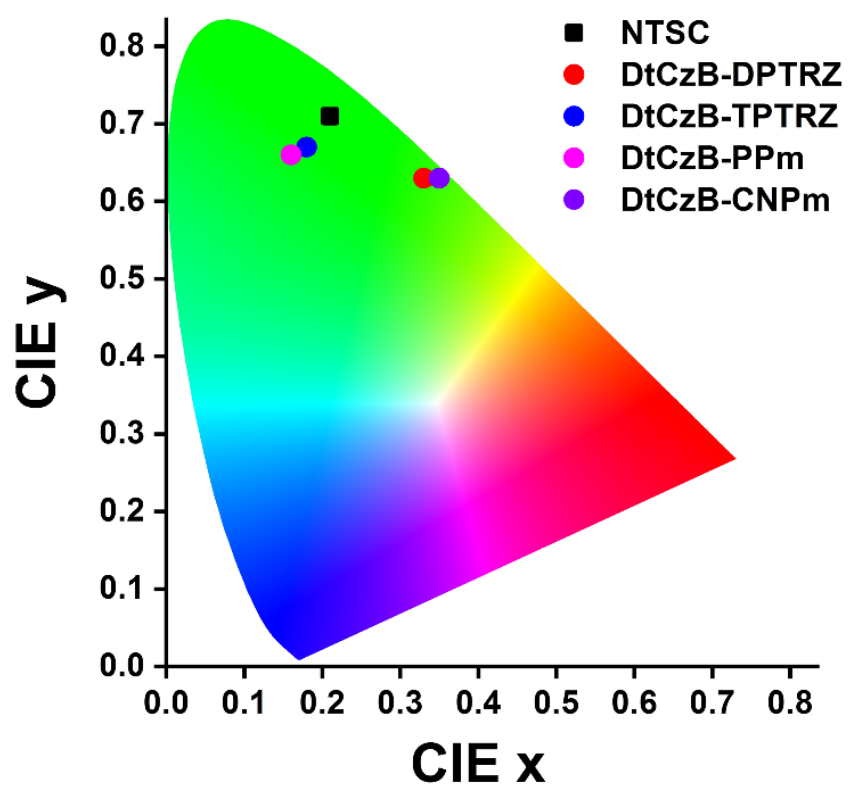

Figure S20. The color coordinates of the investigated compounds-based devices (3 wt $\%$ doping concentration) on the CIE 1931 color space. 


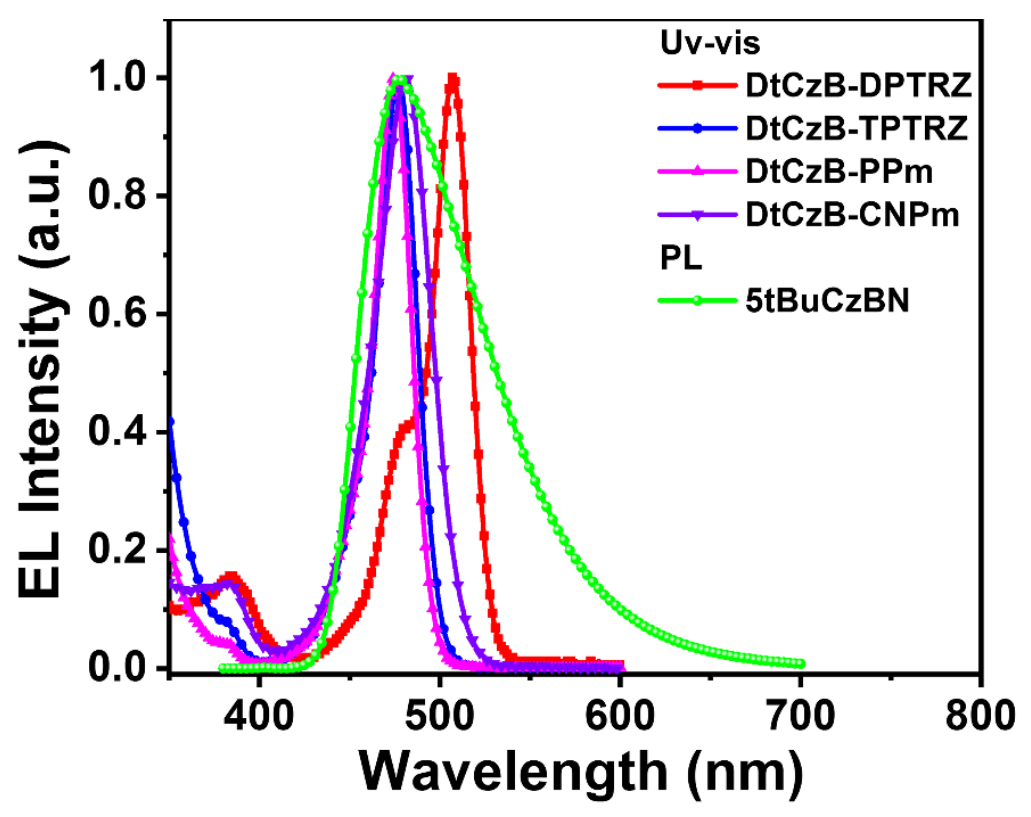

Figure S21. UV-vis absorption spectrum of the investigated compounds and PL spectrum of $5 \mathrm{tBuCzBN}$ in toluene solution $\left(1 \times 10^{-5} \mathrm{M}, 298 \mathrm{~K}\right)$.

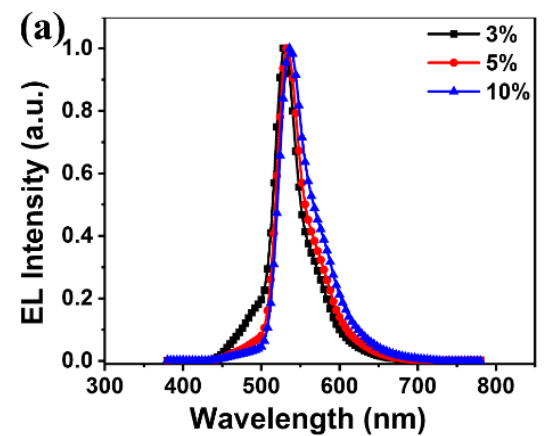

(c)

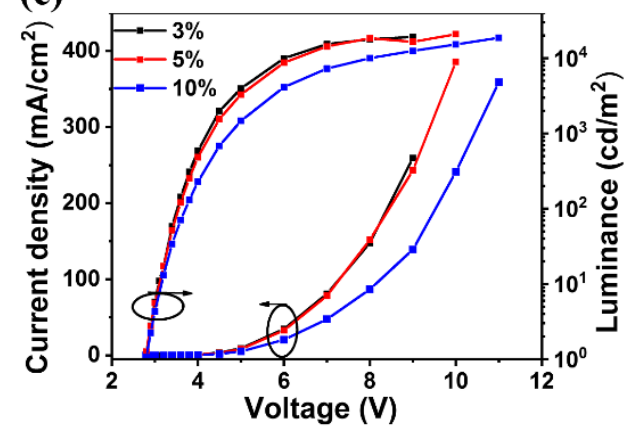

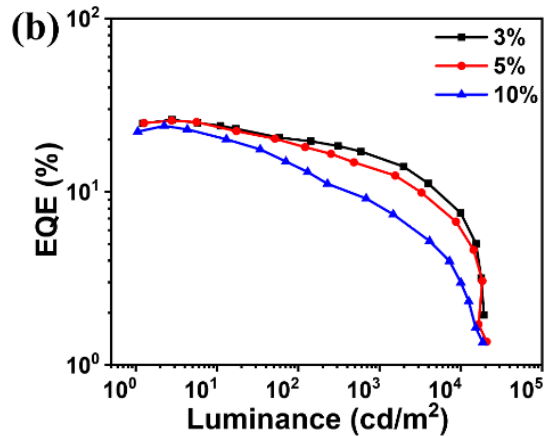

(d)

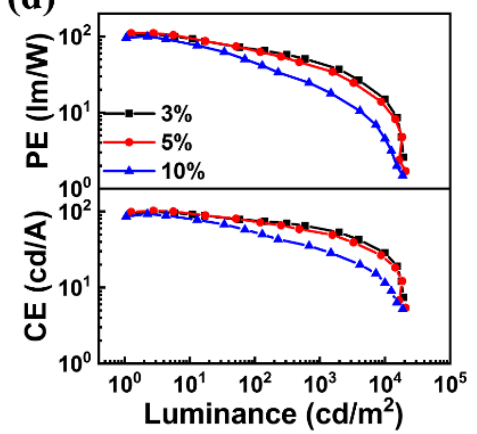

DtCzB-DPTRZ 

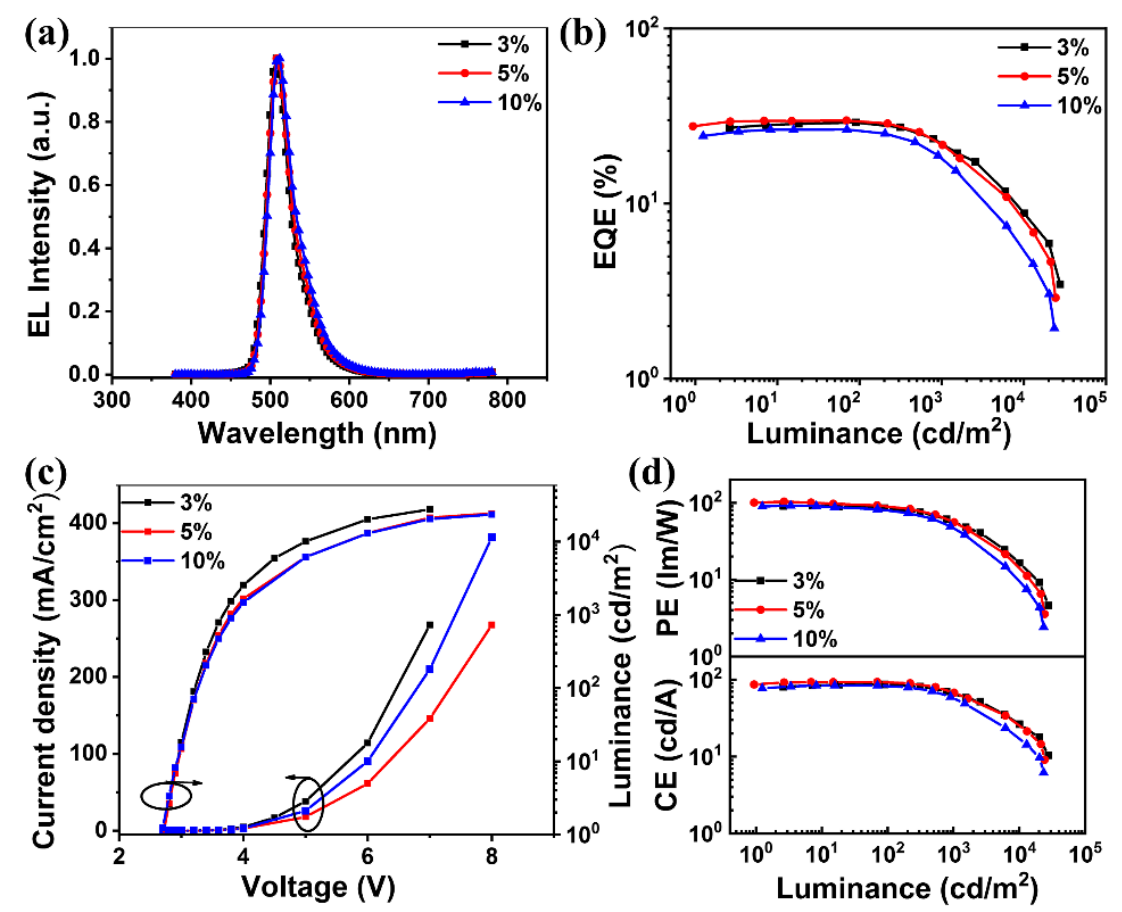

(d)

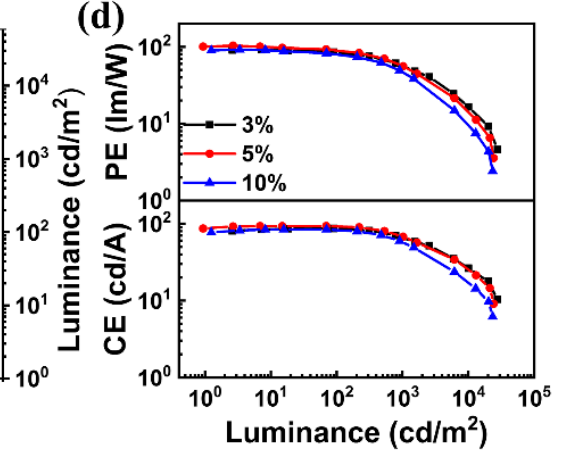

DtCzB-PPm
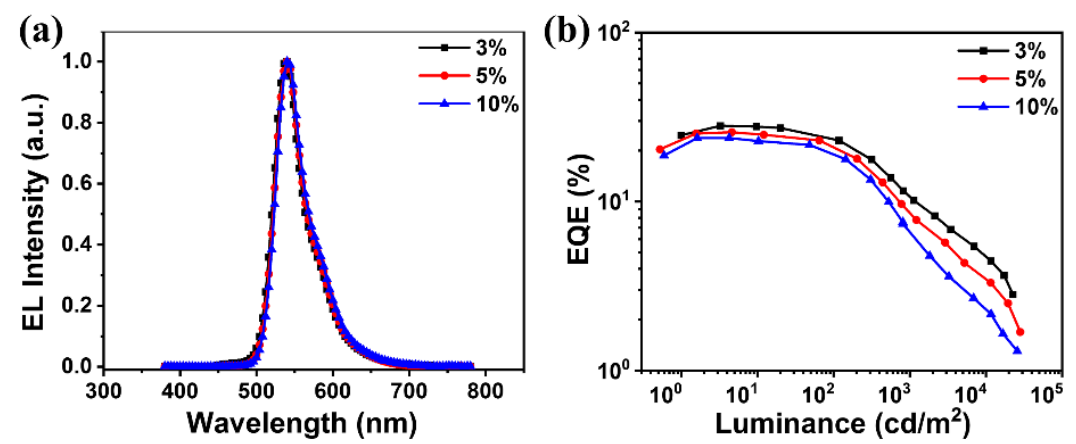

(c)

(d)

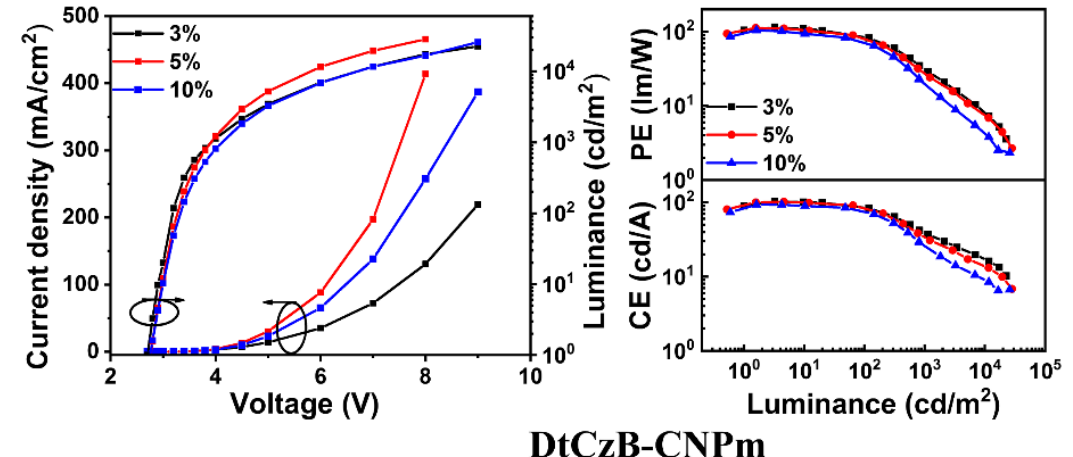

DtCzB-CNPm

Figure S22. The EL characteristics of the devices with the configuration of ITO/TAPC $(50 \mathrm{~nm}) / \mathrm{TCTA}(5 \mathrm{~nm}) / \mathrm{PhCzBCz}: 15 \mathrm{wt} \%$ 5tBuCzBN: $\mathrm{x}$ wt $\%$ the investigated compounds $(30 \mathrm{~nm}) / \mathrm{TmPyPB}(30 \mathrm{~nm}) / \mathrm{LiF}(1 \mathrm{~nm}) / \mathrm{Al}(100 \mathrm{~nm})(\mathrm{x}=3,5,10)$. a) EL spectra. b) EQE- $L$ curves. c) $J-V-L$ curves. d) CE- $L$ and PE- $L$ curves. 


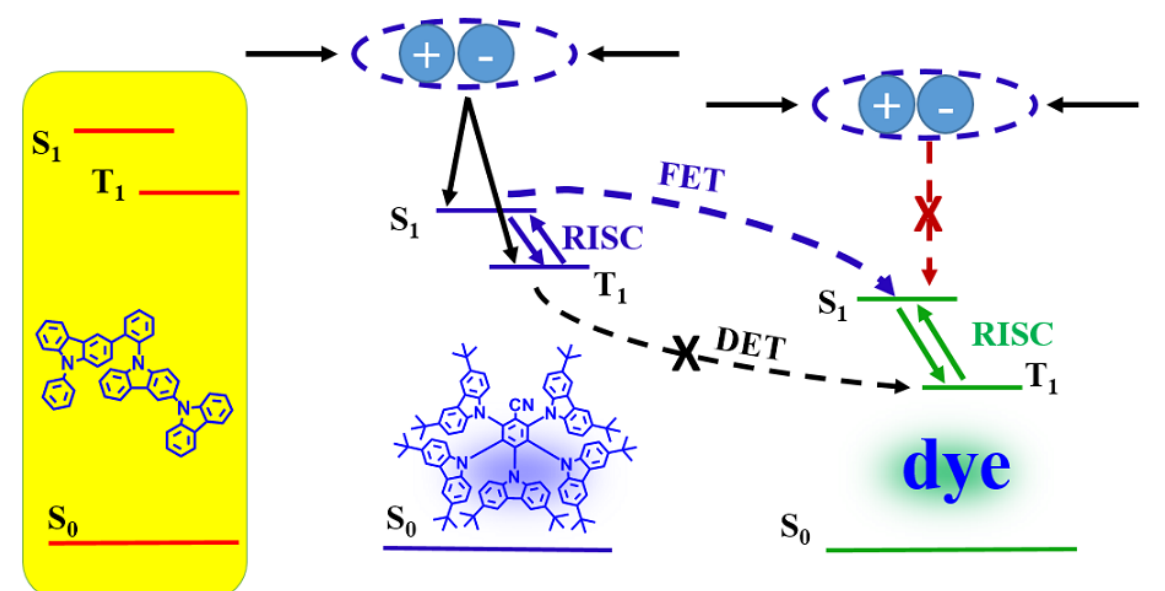

Figure S23. Schematic illustration of energy transfer mechanism in the EML consisting of $\mathrm{PhCzBCz}: 5 \mathrm{tBuCzBN}$-assistant dopant:fluorescent dye under electrical excitation.
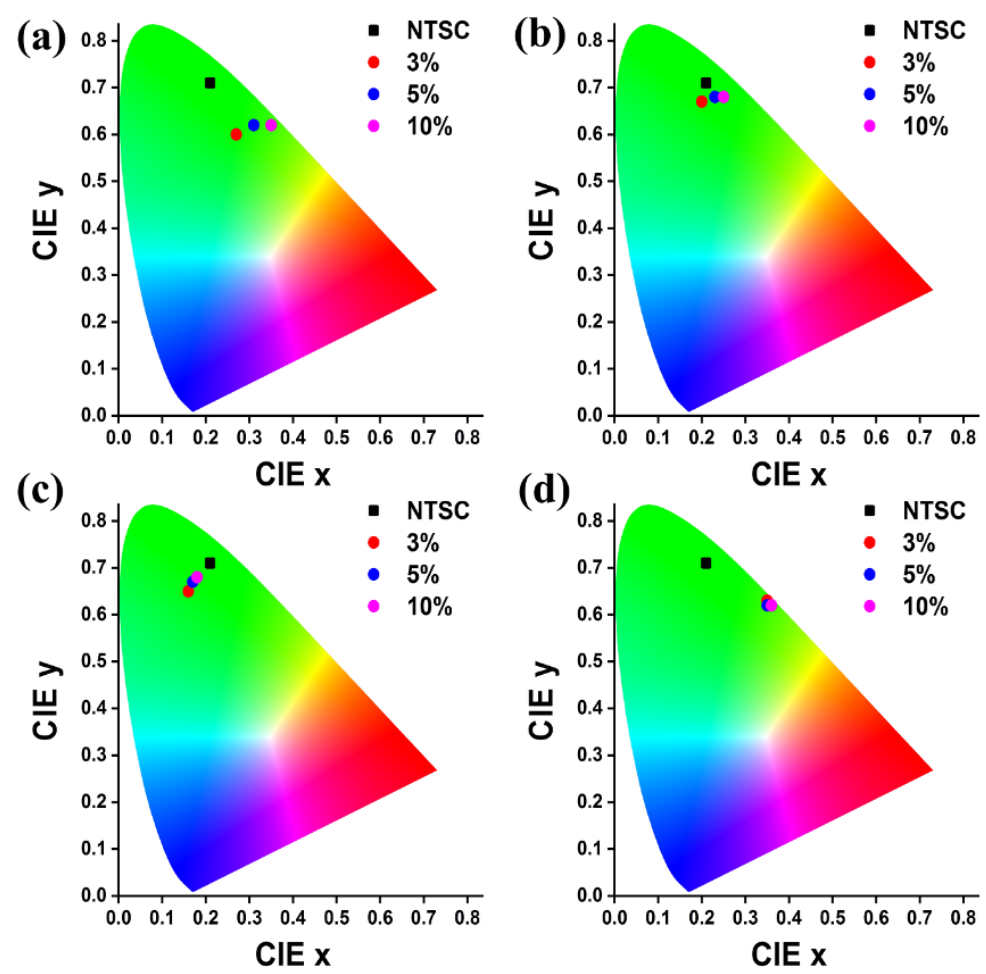

Figure S24. The color coordinates of the investigated compounds-based devices with 5tBuCzBN-assistant dopant on the CIE 1931 color space for DtCzB-DPTRZ (a), DtCzB-TPTRZ (b), DtCzB-PPm (c) and DtCzB-CNPm (d). 

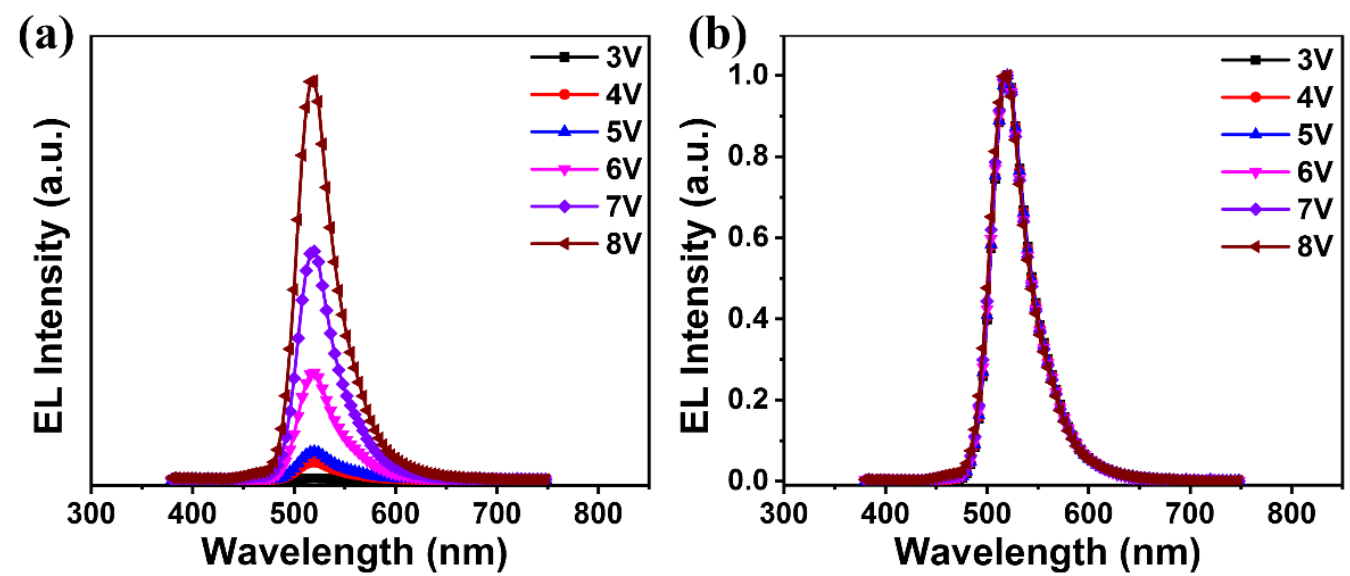

Figure S25. The a) original b) normalized EL spectra operated at different voltages of the DtCzB-TPTRZ-based device ( $5 \mathrm{wt} \%$ doping concentration) with $5 \mathrm{tBuCzBN}$ assistant dopant.

Table S1. Summary of PL spectra data in different polar solvents of the investigated compounds.

\begin{tabular}{|c|c|c|c|c|}
\hline compound & $\begin{array}{c}\text { n-hexane } \\
\lambda_{\text {em }}{ }^{\text {a) }} / \\
\text { FWHM }^{\text {b) }}[\mathrm{nm}]\end{array}$ & $\begin{array}{c}\text { toluene } \\
\lambda_{\mathrm{em}^{\mathrm{a}}} / \\
\mathrm{FWHM}^{\mathrm{b})}[\mathrm{nm}]\end{array}$ & $\begin{array}{c}\text { THF } \\
\lambda_{\mathrm{em}}^{\mathrm{a})} / \\
\mathrm{FWHM}^{\mathrm{b})}[\mathrm{nm}]\end{array}$ & $\begin{array}{c}\text { DMF } \\
\lambda_{\text {em }}^{\text {a) }} / \\
\text { FWHM }^{\text {b) }}[\mathrm{nm}]\end{array}$ \\
\hline DtCzB-DPTRZ & $513 / 19$ & $521 / 24$ & $522 / 26$ & $534 / 52$ \\
\hline DtCzB-TPTRZ & $491 / 22$ & $501 / 27$ & $504 / 29$ & $504 / 35$ \\
\hline DtCzB-PPm & $482 / 20$ & $499 / 25$ & $499 / 25$ & $500 / 30$ \\
\hline DtCzB-CNPm & $500 / 29$ & $515 / 36$ & $520 / 44$ & $531 / 65$ \\
\hline
\end{tabular}

a) PL peak wavelength. ${ }^{\text {b) }}$ Full width at half maximum.

Table S2. Summary of PL spectra data of $3 \mathrm{wt} \%$ doping concentration of the investigated compounds in $\mathrm{PhCzBCz}$ deposited films.

\begin{tabular}{ccc}
\hline compound & $\lambda_{\mathrm{em}}{ }^{\text {a) }}[\mathrm{nm}]$ & FWHM $^{\text {b) }}[\mathrm{nm}]$ \\
\hline DtCzB-DPTRZ & 536 & 43 \\
DtCZB-TPTRZ & 520 & 41 \\
DtCzB-PPm & 510 & 36 \\
DtCzB-CNPm & 543 & 50 \\
\hline
\end{tabular}

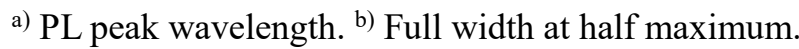


Table S3. Summary of photophysical data of $3 \mathrm{wt} \%$ doping concentration of the investigated compounds in $\mathrm{PhCzBCz}$ deposited films.

\begin{tabular}{ccccc}
\hline compound & $\begin{array}{c}\text { DtCZB- } \\
\text { DPTRZ }\end{array}$ & $\begin{array}{c}\text { DtCzB- } \\
\text { TPTRZ }\end{array}$ & $\begin{array}{c}\text { DtCzB- } \\
\text { PPm }\end{array}$ & $\begin{array}{c}\text { DtCZB- } \\
\text { CNPm }\end{array}$ \\
\hline$\Phi_{\mathrm{PL}}{ }^{\mathrm{a})}[\%]$ & 87 & 95 & 94 & 87 \\
$\Phi_{\mathrm{F}}{ }^{\mathrm{b})}[\%]$ & 74.0 & 63.7 & 63.9 & 72.2 \\
$\Phi_{\mathrm{TADF}}{ }^{\mathrm{c})}[\%]$ & 13.0 & 31.3 & 30.1 & 14.8 \\
$\tau_{\mathrm{F}}{ }^{\mathrm{d})}[\mathrm{ns}]$ & 13.1 & 8.7 & 8.3 & 14.2 \\
$\operatorname{Ref}_{\mathrm{F}}{ }^{\mathrm{e})}[\%]$ & 85 & 67 & 68 & 83 \\
$\tau_{\mathrm{TADF}}{ }^{\mathrm{f}}[\mu \mathrm{s}]$ & 787.5 & 83.5 & 86.5 & 524.3 \\
$\operatorname{Ref}_{\mathrm{TADF}}^{\mathrm{g})}[\%]$ & 15 & 33 & 32 & 17 \\
$k_{\mathrm{F}}^{\mathrm{h})}\left[10^{7} \mathrm{~s}^{-1}\right]$ & 5.65 & 7.32 & 7.70 & 5.08 \\
$k_{\mathrm{IC}}{ }^{\mathrm{i})}\left[10^{7} \mathrm{~s}^{-1}\right]$ & 0.84 & 0.39 & 0.49 & 0.76 \\
$k_{\mathrm{ISC}}{ }^{\mathrm{j})}\left[10^{7} \mathrm{~s}^{-1}\right]$ & 1.14 & 3.79 & 3.86 & 1.20 \\
$k_{\mathrm{TADF}}{ }^{\mathrm{k})}\left[10^{4} \mathrm{~s}^{-1}\right]$ & 0.11 & 1.14 & 1.09 & 0.17 \\
$k_{\left.\mathrm{RISC}^{\mathrm{l}}\right)}\left[10^{4} \mathrm{~s}^{-1}\right]$ & 0.10 & 1.08 & 1.02 & 0.14 \\
$\Phi_{\mathrm{ISC}}{ }^{\mathrm{m})}[\%]$ & 14.94 & 32.95 & 32.02 & 17.01
\end{tabular}

a) The total photoluminescence quantum yield $\left(\Phi_{\mathrm{PL}}\right) .{ }^{\text {b) }}$ The prompt fluorescent $\left(\Phi_{\mathrm{F}}\right)$ component of $\Phi_{\mathrm{PL}} .{ }^{\mathrm{c})}$ The delayed fluorescent ( $\Phi_{\mathrm{TADF}}$ ) component of $\Phi_{\mathrm{PL}}{ }^{\mathrm{d})}$ The lifetime of prompt fluorescence $\left(\tau_{\mathrm{F}}\right) .{ }^{\text {e) }}$ The proportion of prompt fluorescence lifetime. ${ }^{\mathrm{f}}$ The lifetime of delayed fluorescence $\left(\tau_{\mathrm{TADF}}\right)$. g) The proportion of prompt fluorescence lifetime. ${ }^{\text {h) }}$ The rate constant of prompt fluorescence $\left(k_{\mathrm{F}}\right)$. i) The rate constant of internal conversion $\left(k_{\mathrm{IC}}\right) .{ }^{\mathrm{j})}$ The rate constant of TADF $\left(k_{\mathrm{TADF}}\right) .{ }^{\mathrm{k})}$ The rate constant of intersystem crossing $\left(k_{\mathrm{ISC}}\right) .{ }^{1)}$ The rate constant of reverse intersystem crossing $\left(k_{\mathrm{RISC}}\right)$. m) The efficiency of ISC $\left(\Phi_{\text {ISC }}\right)$. 
Table S4. Summary of the EL data of the investigated compounds-based devices.

\begin{tabular}{|c|c|c|c|c|c|c|c|c|}
\hline compound & $\begin{array}{l}\lambda_{\mathrm{em}}{ }^{\mathrm{a})} \\
{[\mathrm{nm}]}\end{array}$ & $\begin{array}{c}\mathrm{FWHM}^{\mathrm{b})} \\
{[\mathrm{nm}]}\end{array}$ & $\begin{array}{l}V_{\text {on }}{ }^{c} \\
{[\mathrm{~V}]}\end{array}$ & $\begin{array}{c}L_{\max }{ }^{\mathrm{d})} \\
{\left[\mathrm{cd} \mathrm{m}^{-2}\right]}\end{array}$ & $\begin{array}{l}E_{\max }{ }^{\mathrm{e})} \\
{\left[\mathrm{cd} \mathrm{A}^{-1}\right]}\end{array}$ & $\begin{array}{c}P E_{\max }^{f)} \\
{\left[\operatorname{Im~} W^{-1}\right]}\end{array}$ & $\begin{array}{c}\text { EQE }^{g)} \\
{[\%]}\end{array}$ & $\operatorname{CIE}(x, y)^{h)}$ \\
\hline DtCzB-DPTRZ & 532 & 39 & 3.0 & 16180 & 88.6 & 92.7 & $24.6 / 7.5 / 4.7$ & $(0.33,0.63)$ \\
\hline DtCzB-TPTRZ & 516 & 38 & 2.9 & 16550 & 93.2 & 98.8 & $\begin{array}{l}29.8 / 26.4 / 12 \\
4\end{array}$ & $(0.18,0.67)$ \\
\hline DtCzB-PPm & 508 & 33 & 2.9 & 13280 & 87.5 & 92.1 & $\begin{array}{l}28.6 / 24.3 / 10 \\
2\end{array}$ & $(0.16,0.66)$ \\
\hline DtCzB-CNPm & 540 & 44 & 2.9 & 13390 & 99.1 & 107.4 & $25.0 / 14.4 / 5.7$ & $(0.35,0.63)$ \\
\hline
\end{tabular}

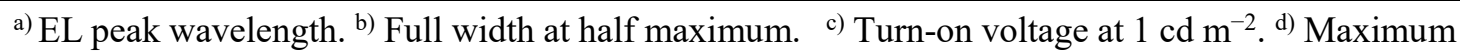
luminance. ${ }^{\text {e) }}$ Maximum current efficiency. ${ }^{\text {f) }}$ Maximum power efficiency. ${ }^{\text {g) }}$ Maximum external quantum efficiency, and values at 100 and $1000 \mathrm{~cd} \mathrm{~m}^{-2}$, respectively. ${ }^{\text {h) }}$ Value taken at $100 \mathrm{~cd} \mathrm{~m}^{-2}$.

Table S5. Summary of the EL data of the investigated compounds-based devices with $5 \mathrm{tBuCzBN}$-assistant dopant.

\section{DtCzB-DPTRZ}

\begin{tabular}{|c|c|c|c|c|c|c|c|c|}
\hline x wt\% & $\begin{array}{l}\lambda_{\mathrm{em}}{ }^{\mathrm{a})} \\
{[\mathrm{nm}]}\end{array}$ & $\begin{array}{c}\text { FWHM }^{\mathrm{b})} \\
{[\mathrm{nm}]}\end{array}$ & $\begin{array}{l}V_{\text {on }}{ }^{c} \\
{[V]}\end{array}$ & $\begin{array}{c}L_{\max }{ }^{\mathrm{d})} \\
{\left[\mathrm{cd} \mathrm{m}^{-2}\right]}\end{array}$ & $\begin{array}{l}E_{\max }{ }^{\mathrm{e})} \\
{\left[\mathrm{cd} \mathrm{A}^{-1}\right]}\end{array}$ & $\begin{array}{c}P E_{\max }^{f)} \\
{\left[\operatorname{Im~} W^{-1}\right]}\end{array}$ & $\begin{array}{c}\text { EQE }^{\mathrm{g})} \\
{[\%]}\end{array}$ & $\operatorname{CIE}(x, y)^{h)}$ \\
\hline 3 & 528 & 36 & 2.8 & 19210 & 99.1 & 107.3 & $26.0 / 20.0 / 15.6$ & $(0.27,0.60)$ \\
\hline 5 & 532 & 38 & 2.8 & 20820 & 102.1 & 110.7 & 25.8/18.6/11.4 & $(0.31,0.62)$ \\
\hline 10 & 536 & 46 & 2.8 & 18690 & 92.5 & 100.2 & $24.0 / 14.0 / 5.0$ & $(0.35,0.62)$ \\
\hline \multicolumn{9}{|c|}{ DtCzB-PPm } \\
\hline$x$ wt\% & $\begin{array}{l}\lambda_{\mathrm{em}}{ }^{\mathrm{a})} \\
{[\mathrm{nm}]}\end{array}$ & $\begin{array}{c}\mathrm{FWHM}^{\mathrm{b})} \\
{[\mathrm{nm}]}\end{array}$ & $\begin{array}{l}V_{\text {on }}{ }^{\mathrm{c}} \\
{[\mathrm{V}]}\end{array}$ & $\begin{array}{c}L_{\max }{ }^{\mathrm{d})} \\
{\left[\mathrm{cd} \mathrm{m}^{-2}\right]}\end{array}$ & $\begin{array}{l}\mathrm{CE}_{\max }{ }^{\mathrm{e})} \\
{\left[\mathrm{cd} \mathrm{A}{ }^{-1}\right]}\end{array}$ & $\begin{array}{c}\left.\mathrm{PE}_{\max }{ }^{\mathrm{f}}\right) \\
{\left[\operatorname{lm~} \mathrm{W}^{-1}\right]}\end{array}$ & $\begin{array}{c}\mathrm{EQE}^{\mathrm{g})} \\
{[\%]}\end{array}$ & $\operatorname{CIE}(x, y)^{h)}$ \\
\hline 3 & 508 & 33 & 2.8 & 27680 & 86.8 & 90.9 & $29.0 / 28.9 / 21.9$ & $(0.16,0.65)$ \\
\hline 5 & 508 & 35 & 2.8 & 24310 & 93.3 & 103.3 & $29.8 / 29.4 / 21.7$ & $(0.17,0.67)$ \\
\hline 10 & 512 & 37 & 2.8 & 23510 & 84.0 & 91.8 & 26.5/26.0/18.1 & $(0.18,0.68)$ \\
\hline \multicolumn{9}{|c|}{ DtCzB-CNPm } \\
\hline$x w t \%$ & $\begin{array}{l}\lambda_{\text {em }}^{\text {a) }} \\
{[\mathrm{nm}]}\end{array}$ & $\begin{array}{c}\mathrm{FWHM}^{\mathrm{b})} \\
{[\mathrm{nm}]}\end{array}$ & $\begin{array}{l}V_{\text {on }}{ }^{\mathrm{c}} \\
{[\mathrm{V}]}\end{array}$ & $\begin{array}{c}L_{\max }{ }^{\mathrm{d})} \\
{\left[\mathrm{cd} \mathrm{m}^{-2}\right]}\end{array}$ & $\begin{array}{l}\mathrm{CE}_{\max }{ }^{\mathrm{e})} \\
{\left[\mathrm{cd} \mathrm{A^{-1 } ]}\right.}\end{array}$ & $\begin{array}{c}\mathrm{PE}_{\max }^{\mathrm{f})} \\
{\left[\mathrm{Im} \mathrm{W}^{-1}\right]}\end{array}$ & $\begin{array}{c}\text { EQE }^{\mathrm{g})} \\
{[\%]}\end{array}$ & $\operatorname{CIE}(x, y)^{h)}$ \\
\hline 3 & 540 & 44 & 2.7 & 22520 & 102.1 & 114.5 & $28.1 / 23.4 / 10.7$ & $(0.35,0.63)$ \\
\hline 5 & 540 & 44 & 2.8 & 28280 & 101.9 & 112.3 & $25.7 / 20.9 / 8.5$ & $(0.35,0.62)$ \\
\hline 10 & 540 & 45 & 2.8 & 25840 & 93.0 & 104.4 & 23.8/19.0/6.5 & $(0.36,0.62)$ \\
\hline
\end{tabular}

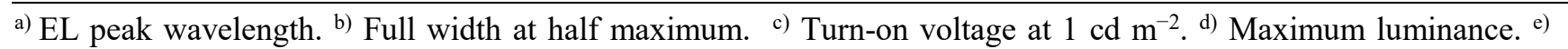
Maximum current efficiency. ${ }^{\mathrm{f}}$ Maximum power efficiency. ${ }^{\mathrm{g}}$ Maximum external quantum efficiency, and values at 100 and $1000 \mathrm{~cd} \mathrm{~m}^{-2}$, respectively. ${ }^{\text {h) }}$ Value taken at $100 \mathrm{~cd} \mathrm{~m}^{-2}$. 


\section{References}

(1) A. D. Becke, J. Chem. Phys. 1993, 98, 5648-5652.

(2) C. Lee, W. Yang, R. G. Parr, Phys. Rev. B 1988, 37, 785-789.

(3) R. Krishnan, J. S. Binkley, R. Seeger, J. Pople, J. Chem. Phys. 1980, 72, 650-654.

(4) S. Grimme, J. Antony, S. Ehrlich, H. Krieg, J. Chem. Phys. 2010, 132, 154104.

(5) Gaussian 09, Revision D.01, M. J. Frisch, G. W. Trucks, H. B. Schlegel, G. E. Scuseria, M. A. Robb, J. R. Cheeseman, G. Scalmani, V. Barone, B. Mennucci, G. A. Petersson, H. Nakatsuji, M. Caricato, X. Li, H. P. Hratchian, A. F. Izmaylov, J. Bloino, G. Zheng, J. L. Sonnenberg, M. Hada, M. Ehara, K. Toyota, R. Fukuda, J. Hasegawa, M. Ishida, T. Nakajima, Y. Honda, O. Kitao, H. Nakai, T. Vreven, J. A. Montgomery, Jr., J. E. Peralta, F. Ogliaro, M. Bearpark, J. J. Heyd, E. Brothers, K. N. Kudin, V. N. Staroverov, T. Keith, R. Kobayashi, J. Normand, K. Raghavachari, A. Rendell, J. C. Burant, S. S. Iyengar, J. Tomasi, M. Cossi, N. Rega, J. M. Millam, M. Klene, J. E. Knox, J. B. Cross, V. Bakken, C. Adamo, J. Jaramillo, R. Gomperts, R. E. Stratmann, O. Yazyev, A. J. Austin, R. Cammi, C. Pomelli, J. W. Ochterski, R. L. Martin, K. Morokuma, V. G. Zakrzewski, G. A. Voth, P. Salvador, J. J. Dannenberg, S. Dapprich, A. D. Daniels, O. Farkas, J. B. Foresman, J. V. Ortiz, J. Cioslowski, and D. J. Fox, Gaussian, Inc., Wallingford CT, 2013.

(6) Humphrey, W.; Dalke, A.; Schulten, K. VMD: visual molecular dynamics. $J$. Mol.Graph. 1996, 14, 33-38.

[7] B. S. Brunschwig, J. Logan, M. D. Newton, N. Sutin, J. Am. Chem. Soc. 1980, 102, 5798.

[8] J. L. Bredas, D. Beljonne, V. Coropceanu, J. Cornil, Chem. Rev. 2004, 104, 4971. 
[9] J. E. Norton, J. L. Bredas, J. Am. Chem. Soc. 2008, 130, 12377.

[10] S. Di Motta, E. Di Donato, F. Negri, G. Orlandi, D. Fazzi, C. Castiglioni, J. Am. Chem. Soc. 2009, 131, 6591.

[11] B. Zhang, Y.-H. Kan, Y. Geng, Y.-A. Duan, H.-B. Li, J. Hua, Z.-M. Su, Org. Electron. 2013, 14, 1359.

[12] Y. Zhao, D. G. Truhlar, Theor. Chem. Acc. 2007, 120, 215.

(13) Jeffrey R. Reimers, J. Chem. Phys. 2001, 115, 9103.

(14) Y. Xu, Z. Cheng, Z. Li, B. Liang, J. Wang, J. Wei, Z. Zhang, Y. Wang, Adv. Opt. Mater. 2020, 8, 1902142.

(15) Q. Zhang, H. Kuwabara, W. J. Potscavage, S. Huang, Y. Hatae, T. Shibata, C. Adachi, J. Am. Chem. Soc. 2014, 136, 18070-18081.

(16) Q. Zhang, B. Li, S. Huang, H. Nomura, H. Tanaka, C. Adachi, Nat. Photonics 2014, $8,326-332$.

(17) T.-L. Wu, M.-J. Huang, C.-C. Lin, P.-Y. Huang, T.-Y. Chou, R.-W. Chen-Cheng, H.-W. Lin, R.-S. Liu, C.-H. Cheng, Nat. Photonics 2018, 12, 235-240.

(18) T. Hatakeyama, K. Shiren, K. Nakajima, S. Nomura, S. Nakatsuka, K. Kinoshita, J. Ni, Y. Ono, T. Ikuta, Adv. Mater. 2016, 28, 2777-2781. 